\title{
Meta-marco de la alfabetización digital: análisis comparado de marcos de competencias del Siglo XXI
}

\author{
Meta-framework of digital literacy: comparative analysis \\ of 21 st century skills frameworks
}

María Cristina Martínez Bravo. Universidad de Navarra. España.

mb.macristina@gmail.com

[CV] OG

Charo Sádaba Chalezquer. Universidad de Navarra. España.

csadaba@unav.es

$[\mathrm{CV}] \bigcirc \mathrm{R}^{\mathrm{a}} \mathrm{O}$

Javier Serrano-ruche. Universidad de Navarra. España.

jserrano@unav.es

$[\underline{\mathrm{CV}}]$ (1) $\mathrm{G}$

Cómo citar este artículo / Referencia normalizada

Martínez-Bravo, M.C., Sádaba-Chalezquer, C. y Serrano-Puche, J. (2021). Meta-marco de la alfabetización digital: análisis comparado de marcos de competencias del siglo XXI. Revista Latina de Comunicación Social, 79, 76-110. https://www.doi.org/10.4185/RLCS-2021-1508

\section{RESUMEN}

Introducción: Ante una inminente era digital marcada por la globalización y la innovación tecnológica, diferentes organismos plantearon la importancia de innovar la educación con las denominadas competencias del siglo XXI. La necesidad de nuevas habilidades para participar de la cultura digital es destacada en diferentes propuestas, donde la competencia digital es clave y fundamental para vivir, trabajar y participar en la sociedad del conocimiento. Metodología: Este trabajo tiene por objetivo generar una propuesta integrada de la alfabetización digital mediante un análisis comparado de la competencia digital en ocho marcos de competencias del siglo XXI (ATCS, enGauge, Naep, Nets, OCDE, P21, Unesco, Unión Europea), los cuales son estudiados en tres grandes bloques temáticos: a) definición, b) objetivos y visión y c) competencias y habilidades. Resultados: La alfabetización digital abarca un enfoque holístico, nutrido por diferentes alfabetizaciones, desde el cual se construye un meta-marco con nueve competencias: tres competencias directas, 1)información y datos, 2) comunicación y colaboración y 3) técnica; cinco competencias transversales, 4) resolución de problemas, 5) ciudadanía global y conciencia multicultural, 6) interpersonal, 7) pensamiento de futuro, 8) pensamiento creativo y 9) pensamiento crítico; y 53 habilidades digitales cognitivas, críticas, técnicas, sociales, emocionales y proyectivas. Conclusiones: La alfabetización digital multidimensional consolida la perspectiva tecnosocial para el empoderamiento y apropiación tecnológica, que supera el uso operativo de las herramientas y promueve el uso amplio, significativo e innovador de la tecnología para la construcción de una sociedad equitativa, el empleo digno, la participación social, entre otros propósitos conectados con la Agenda 2030 para el Desarrollo Sostenible. 
PALABRAS CLAVE: competencias del siglo XXI; alfabetización digital; competencia digital; TIC; educación; brecha digital; Objetivos de Desarrollo Sostenible (ODS).

\begin{abstract}
Introduction: Faced with an imminent digital era marked by globalization and technological innovation, different organizations raised the importance of innovating education with the so-called 21 st century competencies. The need for new skills to participate in digital culture is highlighted in the different proposals, where digital competence is key and fundamental to live, work and participate in Knowledge Society. Methodology: This work aims to generate an integrated proposal of digital literacy through a comparative analysis of digital competence in eight frameworks of 21st century skills (ATCS, enGauge, Naep, Nets, OECD, P21, UNESCO, European Union), which they are studied in three main thematic blocks: a) definition, b) objectives and vision, c) competences and abilities. Results: Digital literacy encompasses a holistic approach, nurtured by different literacies, from which a meta-framework with nine competencies is built: three direct competencies, 1) information and data, 2) communication and collaboration, and 3) technical; five transversal competences, 4) problem solving, 5) global citizenship and multicultural awareness, 6) interpersonal, 7) future thinking, 8) creative thinking and 9) critical thinking; and 53 cognitive, critical, technical, social, emotional and projective digital skills. Conclusions: Multidimensional digital literacy consolidates the techno-social perspective for empowerment and technological appropriation, which exceeds the operational use of tools and guarantees the broad, meaningful and innovative use of technology for the construction of an equitable society, decent employment, social participation, among other purposes that are connected with the Sustainable Development Goals.
\end{abstract}

KEYWORDS: 21st century skills; digital literacy; digital competence; ICT; education; digital divide; Sustainable Development Goals (SDGs).

\title{
CONTENIDO
}

1. Introducción. 2. Objetivos y preguntas de investigación. 3. Metodología. 4. Resultados. 5. Discusión y conclusiones. 6. Bibliografía 7. Anexos

\section{Introducción}

La digitalización del mundo se viene gestando desde 1968, cuando Licklider y Taylor - directores de la investigación ARPA - concibieron el experimento militar ARPANET que precedió internet, para dos décadas más tarde unir a cientos de personas de distintos espacios geográficos en las primeras comunidades virtuales (Reindgold, 1996). Aunque el rol inicial del usuario fue más pasivo, este ha ido evolucionando hacia un papel más activo como prosumidor en una cultura participativa (Toffler, 1980; Jenkins, 2005), en la cual ejerce diversos roles de acuerdo a las circunstancias de interacción (Lang et al., 2020).

Si bien internet ha ampliado el acceso al conocimiento y la participación, los debates empiezan a reflexionar acerca del estado de la esfera pública y los nuevos fenómenos y realidades como la «memecracia» y su impacto en los discursos sociales (Fernández-Villanueva y Bayarri Toscano, 2020); la postverdad y los desafíos para la comunicación, la opinión pública y la democracia (Carballo, López-Escobar y McCombs, 2018); el lifelogging (bitácora de vida) y la reconfiguración del yo (Selke, 2016; Franganillo, 2020); la desinformación y sus múltiples formas y riesgos (Salaverría et al., 2020); la ciberseguridad, el bienestar y el cuidado de la salud (Coventry y Branley, 2018); y muchos otros que están transformando la vida, la cultura y el espacio público. 
Este entorno cambiante, a veces nocivo, pone de manifiesto que la tecnología evoluciona con una rapidez superior a la capacidad de respuesta social y regulatoria (Moreno, 2019; Pedrioli, 2020). En consecuencia, ante un volátil, incierto, complejo y ambiguo «mundo V.I.C.A» (Kingsinger y Walch, 2012), nuevas habilidades digitales son necesarias y, sobre todo, un sistema que pueda engranar su desarrollo creando las condiciones adecuadas (Meshcheryakova, Shalnev y Filatova, 2020) para la participación activa, crítica y significativa en la cultura digital.

A inicios del nuevo milenio, ante una inminente era digital y a medida que la sociedad cambiaba, diversos organismos y gobiernos del mundo empezaron a renovar los paradigmas educativos con diferentes propuestas de marcos de referencia o frameworks de las denominadas competencias del siglo XXI, donde la competencia digital es clave (Ananiadou y Claro, 2009; Voogt y Roblin, 2012).

La frase "competencias del Siglo XXI" hace referencia a un concepto paraguas que abarca una serie de aprendizajes que las personas necesitan para su plena participación en esta era como trabajadores y ciudadanos efectivos (Dede, 2016). Para Unesco (2017) estas habilidades contribuyen a la realización de la Agenda 2030 y todos los niños, niñas, adolescentes y personas adultas deben desarrollarlas para acceder a empleos dignos y para una participación plena en la sociedad que contribuya al desarrollo sostenible y la ciudadanía mundial. En las diferentes propuestas de competencias del siglo XXI se hace énfasis en el uso efectivo y crítico de las TIC frente a desafíos presentes y futuros y se recalca que "sin las habilidades del siglo XXI, los estudiantes se preparan para triunfar en el mundo de ayer, no en el de mañana" (NCRL \& Metiri Group, 2003: 4).

La visión holística del término competencia es subrayada en varias propuestas y abarca el desarrollo de habilidades, valores y actitudes (Ala-Mutka, Punie y Redecker, 2007; OCDE, 2019) que permiten manejar la complejidad, la adaptación al cambio y el uso de las TIC de forma "efectiva, eficiente, apropiada, crítica, creativa, autónoma, flexible, ética, reflexiva para el trabajo, el ocio, la participación, el aprendizaje, la socialización, el consumo y el empoderamiento" (Ferrari, 2012: 5).

La alfabetización digital implica una fusión de habilidades cognitivas, críticas, técnicas, sociales, entre otras (Van Laar et al., 2017; Ferrés, Masanet y Mateus, 2018), que empoderan a las personas en el intercambio, la colaboración y la participación a través de las TIC (Reig, 2016). En este sentido, las tendencias globales, como la inteligencia artificial o las tecnologías espaciales, nos hacen reflexionar sobre el desarrollo inaplazable de una visión integral del sistema educativo que supere la visión instrumental de la tecnología. Berger y Frey (2017:13) refuerzan la necesidad de un enfoque multidimensional de las habilidades frente a los desafíos en el sector laboral y la innovación tecnológica, recalcando que:

Es poco probable que los trabajadores, cuyos trabajos requieran de habilidades sociales y emocionales sean reemplazados por la tecnología... que la inteligencia artificial reemplace a aquellos trabajadores cuyos trabajos requieran creatividad. De manera similar, es poco probable que la inteligencia artificial reemplace a los trabajadores cuyos trabajos requieren interacciones sociales complejas. Por lo tanto, para adaptarse a los avances de la tecnología, los trabajadores también deberán adquirir habilidades sociales...

El término competencia tiene una estrecha relación con la empleabilidad y la fuerza de trabajo, sin embargo, su significado ha sido enriquecido en el debate desde múltiples actores (gobiernos, gremios académicos, colectivos sociales, etc). Para muchos este término está limitado a intereses economicistas, dada su relación al llamado "capital humano", es decir a la persona "competente" como medio de producción. Sin embargo, otras posiciones, conectan este término con el denominado empowerment (empoderamiento), vinculado a la capacidad de acción ciudadana y a una larga data de estudios sociales. Desde este último enfoque, como lo resaltan Moya y Tiana (2010), en el contexto 
del proyecto de Ministerio de Educación español COMBAS para el desarrollo curricular de competencias básicas, tener una competencia es "poder" hacer y decidir algo, "poseer un saber" que empodera a una persona.

Si bien se han desarrollado múltiples enfoques de las competencias como el funcional, conductual o constructivista (Trujillo-Segoviano, 2014), este artículo centra la atención en la apropiación del conocimiento para el empoderamiento ciudadano, sin perder el valor que implica para el futuro laboral y el éxito profesional (García-Perez, García-Garnica \& Olmedo-Moreno, 2021) y reconociendo el amplio campo semántico del término competencia (autoridad, competición, capacitación, cualificación, suficiencia, entre otros).

La pandemia causada por el COVID-19 en 2020 ha acelerado la digitalización en diversos ámbitos de la vida como el trabajo, la educación, el sector productivo o la vida social y ha puesto de manifiesto la importancia de establecer guías y protocolos que permitan la inclusión y participación en el mundo digital. No obstante, las investigaciones preliminares anteriores a la emergencia mundial sanitaria, han señalado las dificultades y brechas para alcanzar la equidad digital y social (VanDeursen, 2010; Van-Deursen \& Van-Dijk, 2014), pero también los múltiples beneficios e impactos de la alfabetización digital para el desarrollo, la democracia, los derechos humanos y más (New Media Consortium, 2017; Pangrazio \& Sefton-Green, 2021).

La presente investigación recoge las visiones institucionales de competencias del siglo XXI de ocho organizaciones de diferente alcance (nacional, regional e internacional): ATCS, enGauge, Naep, Nets, OECD, P21, UNESCO, Unión Europea. Para ello se realiza un análisis comparativo de los documentos en tres bloques temáticos: a) definición, b) objetivos y visión y c) competencias y habilidades.

El estudio contempla tres aportes, el primero encaminado a comprender cómo se articula la competencia digital con las competencias del siglo XXI, lo que permitirá que futuros investigadores consideren esto en sus modelos de implementación y evaluación de la competencia. El segundo, entendiendo que existen múltiples alfabetizaciones integradas y abordadas en cada marco, este trabajo integrado permitirá registrar una visión más nutrida. Y finalmente, el tercero, dado que no se ha hecho este análisis de la competencia digital en estas ocho propuestas estudiadas, aunque sí en algunas de ellas (Chu et al., 2017; Pérez-Escoda, García-Ruiz \& Aguaded, 2019), esto permite contribuir con un meta-marco enriquecido por todas estas visiones. Además, cabe resaltar que el llegar a un nivel de detalle de competencias y habilidades favorece a la comprensión del alcance multidimensional de la alfabetización digital.

\section{Objetivos y preguntas de investigación}

La alfabetización digital ha sido nutrida desde diferentes enfoques plasmados en marcos de referencia con visiones diversas. El objetivo de la presente investigación es generar una propuesta integrada de la alfabetización digital y sus competencias a partir del análisis comparado de ocho propuestas de marcos de referencia de competencias del siglo XXI. Para ello se plantean cuatro preguntas de investigación:

1. ¿Qué rol tiene la competencia digital en los marcos de competencias del siglo XXI?

2. ¿Cómo se define la alfabetización digital en los marcos de competencias del siglo XXI?

3. ¿Qué elementos comunes existen en la visión y objetivos de los marcos de referencia de competencias del siglo XXI?

4. ¿Cómo se articulan las diferentes propuestas de competencias de la alfabetización digital de los marcos de competencias del siglo XXI? 
El aporte principal de esta investigación es fortalecer la construcción de una visión holística de la alfabetización digital para el empoderamiento tecnosocial, a partir de una propuesta de meta-marco que ponga en común estas visiones institucionales.

\section{Metodología}

La investigación se enmarca en un estudio comparado de ocho propuestas de marcos de competencias del siglo XXI de diferentes organizaciones. Se parte de la hipótesis de que a pesar de que el enfoque en alfabetización digital y sus competencias pueden ser diferentes en cada propuesta, estas comparten una multiplicidad de relaciones que se enriquecen entre sí. Este estudio busca, por un lado, recoger las visiones de los veinte primeros años del nuevo milenio y, por otro, generar una propuesta con el fin de contribuir a una visión integrada. Para el estudio se han seleccionados ocho casos y se han planteado tres ejes temáticos de análisis descritos a continuación.

\subsection{Selección de casos de análisis}

Se integran ocho propuestas de diferentes organizaciones para el análisis: ATCS, enGauge, Naep, Nets, OECD, P21, UNESCO, Unión Europea (Tabla 1). Los ocho casos seleccionados se han establecido tomando como base un estudio preliminar de Voogt y Roblin (2012) sobre competencias del siglo XXI y sus implicaciones en la política educativa. A partir de esta determinación, se realizó la búsqueda y selección de documentos de los casos en sus últimas versiones (fecha de corte: agosto 2020). En total se revisaron 70 documentos principales y procedimentales (Anexo 1).

Estos casos enriquecen el análisis debido a sus diferentes características a nivel de alcance (3 nacionales, 2 regionales, 3 internacionales), procedencia (gubernamentales, empresa/organización privada y organizaciones internacionales) y enfoques (énfasis en ciertas alfabetizaciones). Finalmente, cabe recalcar que estos casos abarcan un periodo de 20 años, desde la propuesta de enGauge concebida en el año 2000 y publicada en 2002, hasta la propuesta de la OCDE publicada entre 2019 y 2020, lo cual permite generar una línea de tiempo y proyección de la alfabetización digital en relación a las competencias del siglo XXI. 
Tabla 1. Marcos de competencias del siglo XXI comparados en el estudio

\begin{tabular}{|c|c|c|c|c|c|c|}
\hline $\mathbf{N}^{\mathbf{o}}$ & $\begin{array}{l}\text { Nombre de } \\
\text { documento } \\
\text { base }\end{array}$ & Sigla & Organización/Entidad & Alcance & $\begin{array}{l}\text { Documentos } \\
\text { revisados }\end{array}$ & $\begin{array}{l}\text { Enfoque } \\
\text { de } \\
\text { Alfabetización }\end{array}$ \\
\hline 1 & $\begin{array}{l}\text { Assessment and } \\
\text { Teaching of } 21 \\
\text { Century Skills }\end{array}$ & ATCS & $\begin{array}{l}\text { Proyecto Internacional } \\
\text { auspiciado por Cisco, } \\
\text { Intel y Microsoft. }\end{array}$ & Internacional & 9 & $\begin{array}{c}\text { Alfabetización } \\
\text { TIC } \\
\text { Alfabetización } \\
\text { informática e } \\
\text { informacional } \\
\text { Alfabetización } \\
\text { digital* }\end{array}$ \\
\hline 2 & $\begin{array}{l}\text { enGauge 21st } \\
\text { Century Skills: } \\
\text { Literacy in the } \\
\text { Digital Age }\end{array}$ & enGauge & $\begin{array}{l}\text { North Central Regional } \\
\text { Educational Laboratory } \\
\text { (NCREL) y Metiri } \\
\text { Group. Documento } \\
\text { producido con fondos } \\
\text { del Departamento de } \\
\text { Educación de EEUU. }\end{array}$ & Nacional & 1 & $\begin{array}{l}\text { Alfabetización } \\
\text { en la era digital }\end{array}$ \\
\hline 3 & $\begin{array}{l}\text { Technological } \\
\text { Literacy and } \\
\text { Engineering } \\
\text { Framework for } \\
\text { 2018. National } \\
\text { Assessment of } \\
\text { Educational } \\
\text { progress. }\end{array}$ & NAEP & $\begin{array}{c}\text { Desarrollado por WesEd, } \\
\text { solicitado por el } \\
\text { Gobierno de EEUU. }\end{array}$ & Nacional & 4 & $\begin{array}{c}\text { Alfabetización } \\
\text { Tecnológica y en } \\
\text { ingeniería }\end{array}$ \\
\hline 4 & $\begin{array}{l}\text { National } \\
\text { Educational } \\
\text { Technology } \\
\text { Standards } \\
\end{array}$ & NETS & $\begin{array}{l}\text { International Society for } \\
\text { Technology in Education } \\
\text { (ISTE) }\end{array}$ & Nacional & 12 & $\begin{array}{l}\text { Alfabetización } \\
\text { en la era digital }\end{array}$ \\
\hline 5 & $\begin{array}{c}\text { OECD Future } \\
\text { of Education } \\
\text { and Skills } 2030 \\
\end{array}$ & OCDE & $\begin{array}{l}\text { Organización para la } \\
\text { Cooperación y } \\
\text { Desarrollo Económico }\end{array}$ & Regional & 23 & $\begin{array}{c}\text { Alfabetización } \\
\text { digital }\end{array}$ \\
\hline 6 & $\begin{array}{l}\text { Partnership for } \\
\text { 21st century } \\
\text { skills }\end{array}$ & $\mathrm{P} 21$ & $\begin{array}{l}\text { Gobierto de EEUU y } \\
\text { organizaciones privadas } \\
\text { (Apple Computer Inc, } \\
\text { Cisco Systems, Dell } \\
\text { Computer Corporation, } \\
\text { National Education } \\
\text { Asociation, etc) } \\
\end{array}$ & Internacional & 7 & $\begin{array}{l}\text { Alfabetización } \\
\text { Informacional, } \\
\text { mediática y } \\
\text { tecnológica }\end{array}$ \\
\hline 7 & $\begin{array}{c}\text { A Global } \\
\text { Framework of } \\
\text { Reference on } \\
\text { Digital Literacy } \\
\text { Skills for } \\
\text { Indicator } 4.4 .2\end{array}$ & Unesco & $\begin{array}{c}\text { La Organización de las } \\
\text { Naciones Unidas para la } \\
\text { Educación, la Ciencia y } \\
\text { la Cultura (en inglés } \\
\text { United Nations } \\
\text { Educational, Scientific } \\
\text { and Cultural } \\
\text { Organization), UNESCO }\end{array}$ & Internacional & 6 & $\begin{array}{l}\text { Alfabetización } \\
\text { digital }\end{array}$ \\
\hline 8 & $\begin{array}{c}\text { Digital } \\
\text { Competence for } \\
\text { lifelong } \\
\text { Learning }\end{array}$ & UE & Unión Europea & Regional & 8 & $\begin{array}{l}\text { Alfabetización } \\
\text { digital }\end{array}$ \\
\hline
\end{tabular}

Fuente: Elaboración propia a partir de marcos de competencias del siglo XXI analizados. * Se expresa más de un nombre en el marco analizado para referirse a la competencia

\subsection{Análisis comparado}


Los estudios comparativos favorecen la comprensión de realidades a partir de la generalización empírica, ya que permiten "destacar lo peculiar de fenómenos conocidos y sistematizar la información distinguiendo las diferencias con fenómenos o casos similares" (Gómez Días de León y León de la Garza, 2014). Esta investigación apuesta por una estrategia comparativa de sistemas diferentes, que busca indagar en las analogías entre sistemas contrastantes (diferentes frameworks de diferentes organizaciones y alcances) para conocer las relaciones entre variables y analizar las asociaciones a nivel intrasistémico (Villaroel, 2001).

El análisis realizado se enmarca en tres grandes bloques temáticos comparativos: 1) definición de la alfabetización digital, 2) objetivos y visión, 3) competencias y habilidades. Los elementos enunciados constituyen la unidad de análisis del estudio. A partir de esto se establecen dos niveles de análisis: por un lado, se identifican las diferencias y similitudes de los frameworks estudiados, por otro se analiza la articulación de las propuestas a partir de la consistencia de las definiciones de alfabetización digital y de las competencias inmersas.

Para la sistematización de la información se genera una base datos con las diferentes propuestas de definiciones de la alfabetización digital, sus competencias y habilidades, y se levanta una ficha exploratoria de casos (Anexo 2), herramientas con las cuales se establece la comparación en los tres bloques temáticos.

\section{Resultados}

Los resultados son presentados en cuatro apartados que se conectan a su vez con las preguntas de investigación. El primer apartado se centra en el rol de la competencia digital en los marcos de competencias del siglo XXI (P1); el segundo, en la definición de la alfabetización digital que converge de los múltiples aportes (P2); el tercero, enfocado en los objetivos y visión de los frameworks (P3) y, finalmente, el cuarto está enfocado en las relaciones que se encuentran entre frameworks con respecto a las competencias (P4)

\subsection{La competencia digital: una competencia clave en los marcos de competencias del siglo XXI}

Los diferentes marcos de competencias del siglo XXI, planteados como parte de agendas educativas, contemplan un repertorio de habilidades para hacer frente a un mundo en permanente cambio, acelerado por la revolución digital y la innovación tecnológica.

El rol de la competencia digital como competencia central es subrayado por algunos frameworks (Unesco, OCDE, enGauge, Unión Europea) que enfatizan su importancia para el desarrollo de otras competencias. En el análisis se identifican tres estructuras de los documentos estudiados, las cuales muestran el énfasis y la forma cómo se articula la competencia digital con el resto de competencias. En la imagen (1) se representan las estructuras de articulación, donde las letras (A, B, C) representan a otras competencias y se muestra la relación de estas con la competencia digital. A continuación, se describen las categorías:

1. Framework especializado: Se refiere a las propuestas que tienen un marco amplio de competencias del siglo XXI donde está incluida la alfabetización digital, pero además desarrollan un marco especializado y específico para la competencia digital. Este es el caso de las propuestas de la Unión Europea, Unesco y NAEP. 
2. Framework articulado: Se trata de marcos que plantean su propuesta de competencias, donde está incluida la competencia digital y transversalizada en el resto de competencias. En esta categoría están los casos de enGauge, OCDE y NETS.

3. Framework autónomo: Estos marcos de referencia presentan una suma de competencias donde se plantea de forma independiente la competencia digital sin ninguna integración explícita al resto de competencias. En este grupo se encuentran las propuestas de P21 y ATCS.
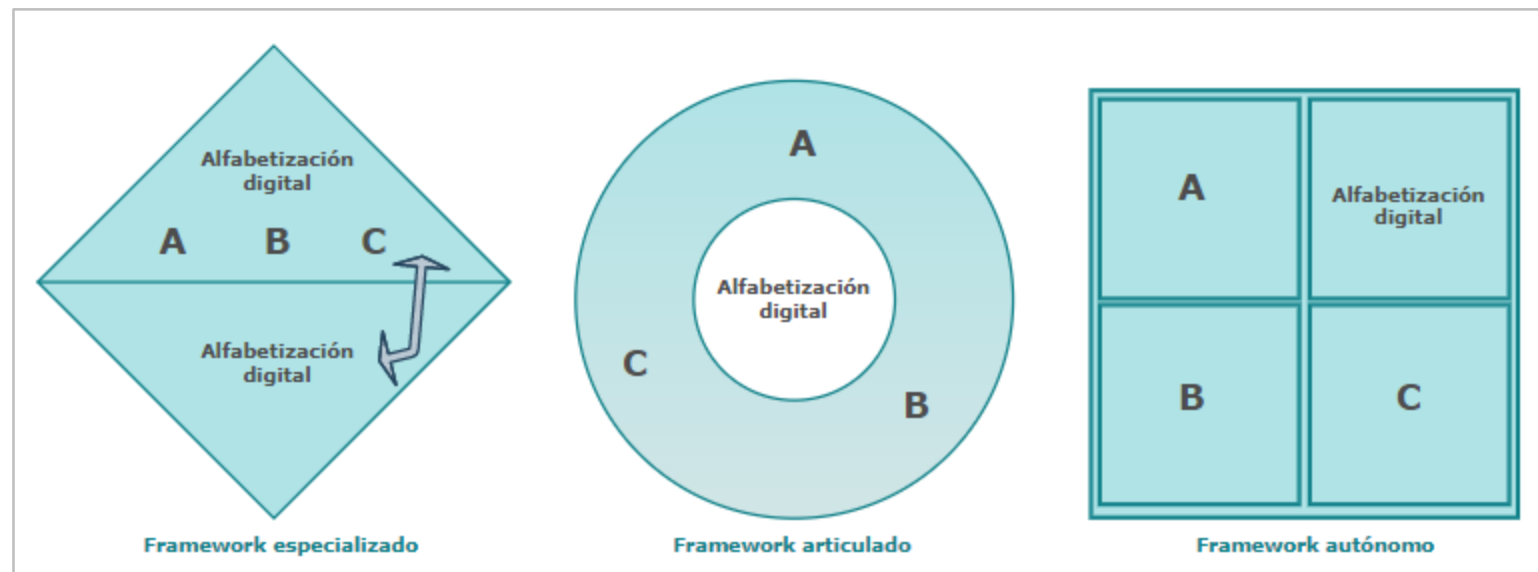

Imagen 1: Articulación de la competencia digital en los marcos de competencias del siglo XXI Fuente: Elaboración propia

Los frameworks especializados y los articulados son más detallados que los autónomos. Estas categorías muestran no solo la profundización del tema en los documentos, sino también la importancia y centralidad de la competencia digital en el contexto de las competencias del siglo XXI.

A nivel general la competencia digital cumple un rol clave debido a que tiene una interacción directa con muchas otras competencias del siglo XXI, impulsándolas a través del uso activo y crítico de las TIC. Es decir, si bien la competencia digital es una parte de las competencias del siglo XXI, su rol es central y transversal porque permite adquirir otras competencias clave. Todo esto plantea también el desafío y la reflexión de la transversalización de la competencia digital en los currículos educativos.

\subsection{La alfabetización digital: un concepto convergente que impulsa el desarrollo humano y económico}

En los marcos de competencias del siglo XXI más actuales, que corresponden a las propuestas de la Unión Europea, Unesco y OCDE, publicados en 2012, 2018 y 2019 respectivamente, existe un consenso en el uso del término "alfabetización digital". Estos hablan de una suma de competencias digitales y habilidades que surgen de diferentes disciplinas. Además, destacan que el término alfabetización digital integra los enfoques de la alfabetización mediática, alfabetización informacional, alfabetización tecnológica y alfabetización TIC.

Los elementos comunes de las definiciones se identifican en el qué y para qué de la alfabetización digital. Si bien todos los marcos de referencia no comparten el mismo nombre para referirse a esta alfabetización digital, el punto de encuentro está en el para qué (Tabla 2). En este sentido encontramos dos visiones: una enfocada en el desarrollo económico y otra en el desarrollo humano basado en las capacidades. 
Por un lado, las propuestas enfatizan que la alfabetización digital es necesaria para tener un trabajo (obtener un empleo o desarrollar un emprendimiento), ser funcional en un ambiente digital y tener éxito en el siglo XXI; por otro, se habla del empoderamiento tanto a nivel personal como social, así como una visión de una ciudadanía efectiva y activa y la construcción de un capital social e intelectual. Ambas visiones se complementan y sobre todo superan el enfoque instrumental de la tecnología alineándose a objetivos sociales enfocados en el acceso y calidad de la educación, erradicación de la pobreza, reducción de inequidades, trabajo digno y crecimiento económico, salud y bienestar, entre otros. Estos puntos de encuentro ponen en magnitud el valor de la alfabetización digital para el desarrollo de la sociedad y el cumplimiento de los objetivos de desarrollo.

Tabla 2. Definiciones de las alfabetizaciones en los marcos analizados

\begin{tabular}{|c|c|c|c|}
\hline Framework & ¿Qué? & ¿Para qué? & $\begin{array}{l}\text { Enfoque } \\
\text { alfabetización }\end{array}$ \\
\hline ATCS & $\begin{array}{l}\text { El término "alfabetización TIC" reúne una amplia gama de } \\
\text { habilidades, como el aprendizaje en redes, la } \\
\text { alfabetización en información, la competencia digital y el } \\
\text { conocimiento tecnológico. Cada uno de ellos contribuye a } \\
\text { aprender a aprender mediante el desarrollo de habilidades } \\
\text { habilitadoras. En primer lugar, funcionar como } \\
\text { consumidor en redes implica obtener, gestionar y utilizar } \\
\text { información y conocimientos de expertos y recursos } \\
\text { digitales compartidos para beneficiar la vida privada y } \\
\text { profesional. En segundo lugar, funcionar como productor } \\
\text { en redes implica crear, desarrollar, organizar y reorganizar } \\
\text { información / conocimiento para contribuir a los recursos } \\
\text { digitales compartidos. En tercer lugar, desarrollar y } \\
\text { sostener el capital social a través de redes implica usar, } \\
\text { desarrollar, moderar, liderar e intermediar las } \\
\text { conectividades dentro y entre individuos y grupos sociales } \\
\text { con el fin de organizar acciones colaborativas, construir } \\
\text { comunidades, mantener la conciencia de las oportunidades } \\
\text { e integrar diversas perspectivas en a nivel comunitario, } \\
\text { social y global. En cuarto lugar, desarrollar y mantener el } \\
\text { capital intelectual a través de redes implica comprender } \\
\text { cómo operan las herramientas, los medios y las redes } \\
\text { sociales y utilizar técnicas apropiadas a través de estos } \\
\text { recursos para construir inteligencia colectiva e integrar } \\
\text { nuevos conocimientos. }\end{array}$ & $\begin{array}{l}\text { Funcionar como } \\
\text { consumidor en } \\
\text { red. Funcionar } \\
\text { como productor } \\
\text { en redes. } \\
\text { Participar en el } \\
\text { desarrollo del } \\
\text { capital social a } \\
\text { través de redes. } \\
\text { Participar en el } \\
\text { capital } \\
\text { intelectual } \\
\text { (inteligencia } \\
\text { colectiva) en } \\
\text { redes. }\end{array}$ & $\begin{array}{l}\text { Alfabetización TIC } \\
\text { Alfabetización } \\
\text { informática } \\
\text { informacional } \\
\text { Alfabetización } \\
\text { digital }\end{array}$ \\
\hline enGauge & $\begin{array}{l}\text { Habilidades necesarias para negociar las complejidades de } \\
\text { la vida }\end{array}$ & $\begin{array}{l}\text { Para lograr el } \\
\text { éxito en el siglo } \\
\text { XXI }\end{array}$ & $\begin{array}{l}\text { Alfabetización en la } \\
\text { era digital }\end{array}$ \\
\hline NAEP & $\begin{array}{l}\text { La "alfabetización en tecnología e ingeniería" se puede } \\
\text { definir de una manera igualmente amplia como la } \\
\text { capacidad para usar, comprender y evaluar la tecnología, } \\
\text { así como para comprender los principios y estrategias } \\
\text { tecnológicos necesarios para desarrollar soluciones y } \\
\text { lograr metas (...) la alfabetización tecnológica incluye } \\
\text { conocimientos, capacidades y habilidades de pensamiento } \\
\text { crítico y toma de decisiones. }\end{array}$ & $\begin{array}{l}\text { Para desarrollar } \\
\text { soluciones y } \\
\text { lograr metas. }\end{array}$ & $\begin{array}{l}\text { Alfabetización } \\
\text { tecnología } \\
\text { ingeniería }\end{array}$ \\
\hline NETS & $\begin{array}{l}\text { No se proporciona una definición general, sino una } \\
\text { definición de cada competencia. }\end{array}$ & N/A & $\begin{array}{l}\text { Alfabetización en la } \\
\text { era digital }\end{array}$ \\
\hline P21 & $\begin{array}{l}\text { Variedad de habilidades funcionales y de pensamiento } \\
\text { crítico relacionadas con la información, los medios y la } \\
\text { tecnología. }\end{array}$ & $\begin{array}{l}\text { Ciudadanos } \quad \mathrm{y} \\
\text { trabajadores } \\
\text { eficaces del } \\
\text { siglo XXI }\end{array}$ & $\begin{array}{l}\text { Alfabetización } \\
\text { informacional, } \\
\text { alfabetización } \\
\text { mediática, } \\
\text { alfabetización TIC }\end{array}$ \\
\hline
\end{tabular}




\begin{tabular}{|c|c|c|c|}
\hline Unesco & $\begin{array}{l}\text { La alfabetización digital es la capacidad de acceder, } \\
\text { gestionar, comprender, integrar, comunicar, evaluar y crear } \\
\text { información de forma segura y adecuada a través de } \\
\text { tecnologías digitales para el empleo, el trabajo decente y el } \\
\text { emprendimiento. }\end{array}$ & $\begin{array}{l}\text { El empleo, } \\
\text { trabajo decente } \\
\mathrm{y} \\
\text { emprendimiento }\end{array}$ & $\begin{array}{l}\text { Alfabetización } \\
\text { digital }\end{array}$ \\
\hline UE & $\begin{array}{l}\text { La competencia digital implica el uso seguro y crítico de la } \\
\text { Tecnología de la Sociedad de la Información (IST) } \\
\text { La competencia digital es el conjunto de conocimientos, } \\
\text { habilidades, actitudes (incluidas habilidades, estrategias, } \\
\text { valores y conciencia) que se requieren cuando se utilizan } \\
\text { las tic y los medios digitales para realizar tareas; resolver } \\
\text { problemas; comunicar; gestionar la información; } \\
\text { colaborar; crear y compartir contenido; y construir } \\
\text { conocimiento de manera efectiva, eficiente, apropiada, } \\
\text { crítica, creativa, autónoma, flexible, ética, reflexiva para el } \\
\text { trabajo, el ocio, la participación, el aprendizaje, la } \\
\text { socialización, el consumo y el empoderamiento. }\end{array}$ & $\begin{array}{l}\text { Para el trabajo, } \\
\text { el ocio, la } \\
\text { participación, el } \\
\text { aprendizaje, la } \\
\text { socialización, el } \\
\text { consumo y el } \\
\text { empoderamiento }\end{array}$ & $\begin{array}{l}\text { Alfabetización } \\
\text { digital }\end{array}$ \\
\hline OCDE & $\begin{array}{l}\text { El concepto de competencia digital es móvil y } \\
\text { multifacético, y cubre muchas áreas y alfabetizaciones, se } \\
\text { encuentra en la convergencia de múltiples campos. Ser } \\
\text { digitalmente competente hoy en día implica la capacidad } \\
\text { de comprender los medios (ya que la mayoría de los } \\
\text { medios han sido / están siendo digitalizados), buscar } \\
\text { información y ser crítico sobre lo que se recupera (dada la } \\
\text { amplia aceptación de Internet) y poder comunicarse con } \\
\text { otros, utilizando una variedad de herramientas y } \\
\text { aplicaciones digitales (móvil, Internet). Estar alfabetizado } \\
\text { digitalmente requiere la capacidad de leer, interpretar, dar } \\
\text { significado y comunicarse a través de textos digitales y } \\
\text { fuentes de una variedad de medios en línea. También } \\
\text { requiere la capacidad de evaluar críticamente y filtrar } \\
\text { información que es tan fácil de producir, acceder y hacer } \\
\text { pública. La alfabetización de datos requiere no solo poder } \\
\text { trabajar con fórmulas matemáticas en un libro de } \\
\text { ejercicios, sino también ser competente para navegar, } \\
\text { interpretar y computar datos diversos en la vida diaria y } \\
\text { contextos profesionales, y comunicarse con datos. La } \\
\text { alfabetización digital se basa en las mismas habilidades } \\
\text { fundamentales que la alfabetización "tradicional"; pero la } \\
\text { alfabetización digital se aplica en contextos digitales y se } \\
\text { basa en nuevas herramientas y competencias digitales. }\end{array}$ & $\begin{array}{l}\begin{array}{l}\text { Para la vida } \\
\text { diaria y los }\end{array} \\
\text { contextos } \\
\text { profesionales. } \\
\text { Para ser } \\
\text { funcional en un } \\
\text { entorno digital. }\end{array}$ & $\begin{array}{l}\text { Alfabetización } \\
\text { digital. } \\
\text { Alfabetización } \\
\text { datos. }\end{array}$ \\
\hline
\end{tabular}

Fuente: Elaboración y traducción propia a partir de marcos: ATCS, enGauge, Naep, Nets, OCDE, P21, Unesco, UE.

La alfabetización digital es un concepto convergente de varias alfabetizaciones, la cual implica más que un enfoque técnico, una visión tecnosocial y crítica. Esta facilita trabajar, vivir y participar en la era digital, lo cual impulsa el desarrollo humano y económico. Este análisis nos conduce a comprender la alfabetización digital como un conjunto de competencias, conocimientos, habilidades y actitudes que permiten el uso seguro y crítico de las TIC, para consumir, producir y participar en el ecosistema digital. Así pues, la alfabetización digital contempla las mismas habilidades fundamentales que la alfabetización tradicional, es decir implica la capacidad de leer, interpretar, dar significado y comunicarse, pero a través de diferentes códigos, formatos y contextos digitales. 


\subsection{Objetivos y visiones que se encuentran en el empoderamiento social y laboral}

El horizonte educativo e institucional de cada propuesta de competencias del siglo XXI es fundamental para comprender la construcción de las visiones sobre la educación del futuro. Los documentos están dirigidos hacia diversos actores del ecosistema de aprendizaje: profesionales de la educación, tomadores de decisiones, hacedores de política pública, autoridades educativas, entre otros. El principal objetivo es repensar la educación, innovar la enseñanza y el aprendizaje, crear un paraguas conceptual que permita una comprensión común para debatir lo que necesitan los estudiantes, los ciudadanos y los trabajadores en la era digital. También se identifica una alineación a las expectativas del sector privado, a los proveedores de servicios y comunidades empresariales, que tienen una estrecha relación con el futuro laboral o con la cobertura de necesidades educativas.

Por su parte, los aprendices son en menor medida destinatarios de estos documentos, aunque son considerados actores fundamentales, ya que estos determinan los conocimientos, habilidades, actitudes y valores que necesitarán para prosperar y dar forma al mundo.

Se identifica en cinco de las ocho propuestas (Unesco, UE, OCDE, enGauge, P21) un enfoque hacia los entornos formales e informales de la alfabetización digital, es decir al aprendizaje a lo largo de la vida que va más allá de las aulas. En la mayoría de estos casos no solo está pensado el aprendizaje temprano en la niñez, sino la participación de ciudadanos de todas las edades. Las otras propuestas se enfocan en el entorno educativo formal (NETS, NAEP y ATCS).

En lo que respecta a los objetivos relativos a procesos educativos, como la implementación y evaluación de la competencia digital, los marcos tienen diversas especializaciones. Por un lado, están aquellos que desarrollan el enfoque de evaluación y/o medición (Unesco, NAEP y ATCS), mientras que otros se centran en la implementación de la competencia (UE, NETS, enGauge, P21). Por su parte, la propuesta de OCDE establece una guía de aprendizaje que establece una visión aspiracional de la educación. Este marco no pretende ser ni un currículo para implementación ni para evaluación, sino una guía de competencias que las personas necesitan para prosperar en el futuro.

A nivel general se distinguen dos tipos de objetivos de las propuestas: operativos (medir indicadores o marco común para operar la educación) y sociales (identificar desafíos para mejorar la educación, guiar a educadores, bien común y equidad). Los frameworks desarrollan uno o los dos objetivos. Por ejemplo, en el caso de Unesco, el objetivo operativo principal de la propuesta es proporcionar indicadores para la medición del objetivo 4.1.1 (derecho a la educación) de la Agenda 2030 para el Desarrollo Sostenible, a su vez este framework también persigue una alineación a otros objetivos de desarrollo (trabajo digno y equidad), conectados con fines socioeconómicos (equidad y reducción de la pobreza).

Con respecto a las visiones, las propuestas apuntan a anticipar el futuro y estar mejor preparados, al bienestar individual y colectivo, al empoderamiento social y ciudadano, a garantizar la equidad, a restar las brechas sociales, a garantizar la participación ciudadana activa, plena y crítica, la toma de decisiones mejor informados, garantizar la participación en la economía y la cultura. La visión más compartida entre las propuestas es la de estar preparados para trabajos innovadores y el desarrollo de habilidades de la fuerza laboral. 


\subsection{Competencias de la alfabetización digital: hacia un enfoque tecnosocial y un marco integrado}

La alfabetización digital en los marcos de referencia del siglo XXI abarca diversas competencias y enfoques, unos más técnicos y otros más tecnosociales. Los marcos de enGauge y de OCDE son los más amplios, es decir contemplan un mayor número de competencias y tienen una mayor diversidad de áreas de conocimiento integradas.

En la tabla (3) se muestra el compendio de competencias identificadas en cada marco de referencia. Es importante subrayar que no existe una estructura uniforme respecto al nivel en que se presenta un enfoque de alfabetización (concepto más amplio) y las competencias (habilidades, actitudes y valores específicos). En la tabla también se señala el rol directo (D) o transversal (T) de las competencias en los frameworks.

Tabla 3. Competencias digitales identificadas en marcos de competencias del siglo XXI estudiados

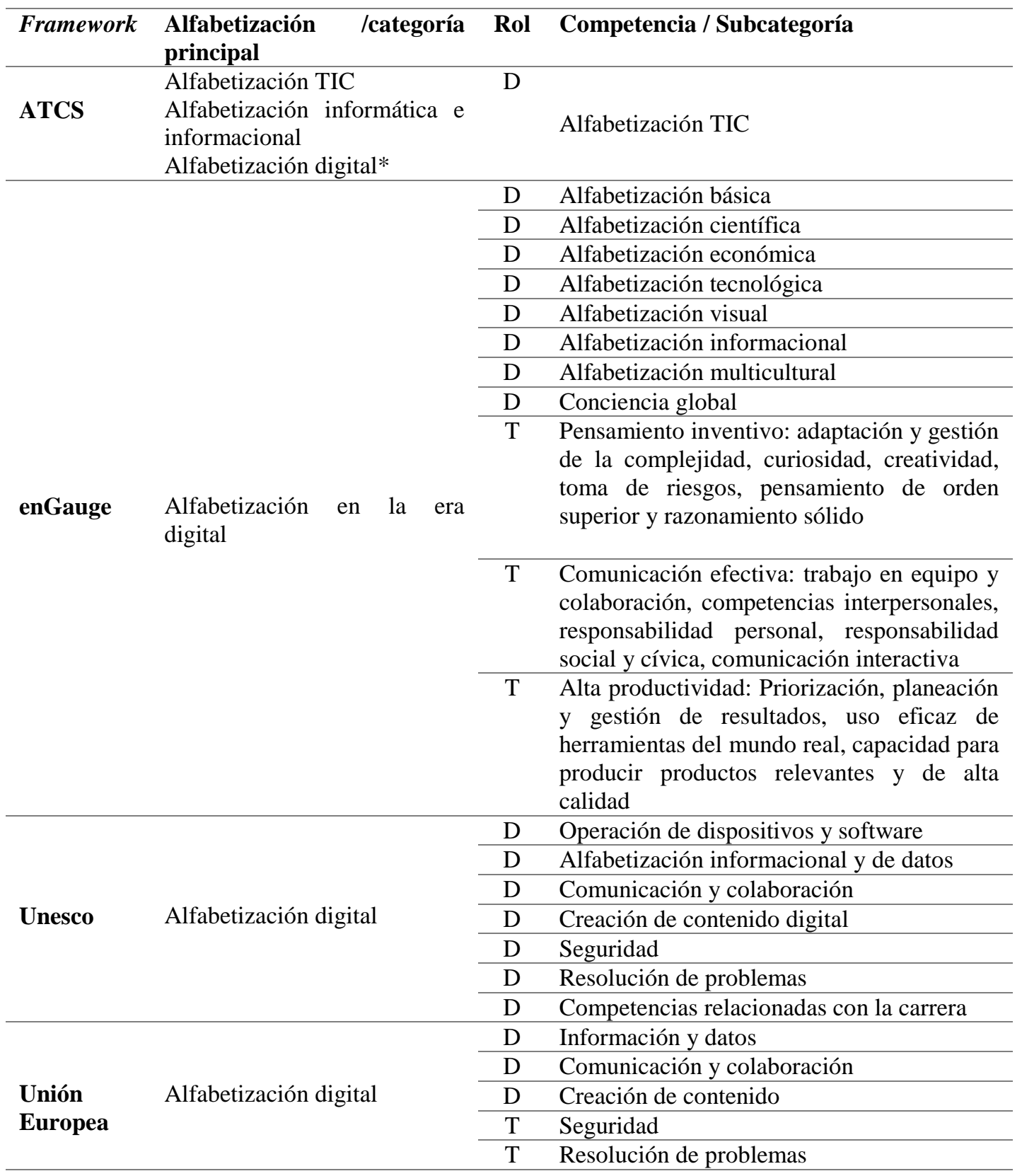




\begin{tabular}{|c|c|c|c|}
\hline \multirow{7}{*}{ NETS } & \multirow{7}{*}{$\begin{array}{l}\text { Alfabetización en la era } \\
\text { digital }\end{array}$} & $\mathrm{D}$ & Aprendiz empoderado \\
\hline & & $\mathrm{D}$ & Ciudadano digital \\
\hline & & $\mathrm{D}$ & Constructor de conocimiento \\
\hline & & $\mathrm{D}$ & Diseñador innovador \\
\hline & & $\mathrm{D}$ & Pensador computacional \\
\hline & & $\mathrm{D}$ & Comunicador creativo \\
\hline & & $\mathrm{D}$ & Colaborador global \\
\hline \multirow{3}{*}{$\mathbf{P 2 1}$} & \multirow{3}{*}{$\begin{array}{l}\text { Alfabetización informacional } \\
\text { Alfabetización mediática } \\
\text { Alfabetización TIC }\end{array}$} & $\mathrm{D}$ & Alfabetización informacional \\
\hline & & $\mathrm{D}$ & Alfabetización mediática \\
\hline & & $\mathrm{D}$ & Alfabetización TIC \\
\hline \multirow{3}{*}{ NAEP } & \multirow{3}{*}{$\begin{array}{l}\text { Alfabetización en tecnología e } \\
\text { ingeniería }\end{array}$} & $\mathrm{D}$ & Tecnología y Sociedad \\
\hline & & $\mathrm{D}$ & Diseño y Sistemas \\
\hline & & $\mathrm{D}$ & $\begin{array}{l}\text { Tecnologías de la } \text { Información } \quad \text { y } \\
\text { Comunicación }\end{array}$ \\
\hline \multirow[t]{5}{*}{ OCDE } & \multirow{5}{*}{$\begin{array}{l}\text { Alfabetización digital } \\
\text { Alfabetización de datos }\end{array}$} & $\mathrm{D} / \mathrm{T}$ & $\begin{array}{l}\text { Alfabetizaciones fundamentales: } \\
\text { - Básica: Literatura y aritmética } \\
\text { - Alfabetización digital, Alfabetización TIC } \\
\text { - Alfabetización de datos } \\
\text { - Alfabetización física y de salud }\end{array}$ \\
\hline & & $\mathrm{D} / \mathrm{T}$ & $\begin{array}{l}\text { Competencias compuestas: } \\
\text { - Competencia global } \\
\text { - Alfabetización mediática } \\
\text { - Alfabetización para el desarrollo sostenible } \\
\text { - Pensamiento computacional, programación } \\
\text { - Alfabetización financiera } \\
\text { - Emprendimiento }\end{array}$ \\
\hline & & $\mathrm{T}$ & $\begin{array}{l}\text { Competencias transformadoras: } \\
\text {-Creación de nuevo valor } \\
\text { - Asumir responsabilidad } \\
\text { - Conciliar conflictos, tensiones y dilemas }\end{array}$ \\
\hline & & $\mathrm{D} / \mathrm{T}$ & $\begin{array}{l}\text { Competencia/habilidades (valores \& } \\
\text { actitudes): } \\
\text { - Habilidades cognitivas y meta-cognitivas: } \\
\text { pensamiento crítico, pensamiento creativo, } \\
\text { aprender a aprender, autonomía. } \\
\text { - Habilidades sociales y emocionales: } \\
\text { empatía, autoeficacia, responsabilidad y } \\
\text { colaboración. } \\
\text { - Habilidades prácticas y físicas: uso de } \\
\text { nuevos dispositivos de tecnología de la } \\
\text { información y la comunicación. }\end{array}$ \\
\hline & & $\mathrm{T}$ & Anticipación - Acción - Reflexión (AAR) \\
\hline
\end{tabular}

Fuente: Elaboración y traducción propia a partir de marcos: ATCS, enGauge, Naep, Nets, OCDE, P21, Unesco, UE. * Se expresa más de un nombre en el marco analizado para referirse a la competencia

En la Tabla (4) se muestran las competencias más y menos recurrentes entre marcos analizados. Las competencias de información, comunicación, colaboración y técnica (TIC) son las que prevalecen en todos. Estos son aportes directos desde las áreas más comunes de investigación que abarcan los estudios de medios, las ciencias de la información, la comunicación, la educación y las ciencias de la computación e ingenierías.

En la mayoría de frameworks también se puede ver una fuerte visión de lo social y multicultural de la mano del enfoque de la participación a través de las tecnologías y la ciudadanía digital. La resolución de problemas y el pensamiento crítico son competencias también recurrentes, aunque en diversas 
estructuras, es decir, no siempre están al nivel de competencias, sino de habilidades o incluso como características transversales. Otras competencias aportan gran valor desde perspectivas creativas, éticas, económicas, futuristas, productivas, científicas, sociales o emocionales.

Tabla 4. Recurrencia de competencias digitales identificadas en los marcos del siglo XXI

\begin{tabular}{|c|c|c|c|c|c|}
\hline $\begin{array}{l}\text { Mencionadas en todos } \\
\text { los marcos }\end{array}$ & $\begin{array}{l}\text { Mencionadas en } \\
\text { mayoría }(5-7) \\
\text { marcos }\end{array}$ & $\begin{array}{r}\text { la } \\
\text { de }\end{array}$ & $\begin{array}{l}\text { Mencionadas } \\
\text { pocos }(2-4) \text { marcos }\end{array}$ & en & $\begin{array}{l}\text { Mencionadas en un solo } \\
\text { marco }\end{array}$ \\
\hline $\begin{array}{l}\text { - Información } \\
\text { - Comunicación } \\
\text { - Colaboración } \\
\text { - Tecnológica (TIC) }\end{array}$ & $\begin{array}{l}\text { - Cultural y Social } \\
\text { - Resolución } \\
\text { problemas } \\
\text { - Pensamiento crítico }\end{array}$ & $\mathrm{de}$ & $\begin{array}{l}\text { - Mediática } \\
\text { - Creatividad } \\
\text { - Datos } \\
\text { - Profesional } \\
\text { - Seguridad } \\
\text { - Creación } \\
\text { contenido } \\
\text { - Responsabilidad } \\
\text { - Básica } \\
\text { - Económica } \\
\text { financiera } \\
\text { - Interpersonal }\end{array}$ & de & $\begin{array}{l}\text { - Salud } \\
\text { - Productividad } \\
\text { - Científica } \\
\text { - Anticipación, reflexión } \\
\text { y acción } \\
\text { - Desarrollo sostenible } \\
\text { - Creación de nuevo } \\
\text { valor } \\
\text { - Autonomía } \\
\text { - Toma de riesgos } \\
\text { - Adaptación } \\
\text { - Aprender a aprender }\end{array}$ \\
\hline
\end{tabular}

Fuente: Elaboración y traducción propia a partir de marcos: ATCS, enGauge, Naep, Nets, OCDE, P21, Unesco, UE.

Para articular las diferentes competencias planteadas en las propuestas se identificaron primero las competencias con coincidencia exacta (recurrentes), segundo las competencias conceptualmente similares con nombres diferentes y, tercero, las competencias que formaban parte de categorías más amplias. Para integrarlas se establecieron dos modalidades: 1) articulación por recurrencia y 2) articulación por relación amplia.

En la Tabla 5 se presentan las competencias integradas y los frameworks donde están localizadas. En la primera categoría de articulación recurrente hay cinco competencias presentes en todos o en la mayoría de marcos. Por su parte, en lo que respecta a la segunda categoría de articulación amplia hay tres competencias, las mismas que se establecen a partir de conceptos integradores que integran diversas habilidades. 
RLCS, Revista Latina de Comunicación Social, 79, 76-110

[Investigación] DOI: 10.4185/RLCS-2021-1508| ISSN 1138-5820| Año 2021

Tabla 5. Articulación de competencias y localización en frameworks

\begin{tabular}{cll}
\hline $\begin{array}{c}\text { Categoría de } \\
\text { articulación }\end{array}$ & \multicolumn{1}{c}{ Competencias } & \multicolumn{1}{c}{ Frameworks } \\
\hline \multirow{2}{*}{ Recurrente } & Información y datos & Todos \\
\cline { 2 - 3 } & Comunicación y colaboración & Todos \\
\cline { 2 - 3 } & Técnica & Todos \\
\cline { 2 - 3 } & Resolución de problemas & ATCS, enGauge, Unesco, UE, Naep, Nets \\
\cline { 2 - 3 } & Ciudadanía global y conciencia multicultural & enGauge, UE, Unesco, Naep, Nets \\
\hline \multirow{2}{*}{ Amplia* } & Interpersonal & OCDE, enGauge, UE, Unesco \\
\cline { 2 - 3 } & Pensamiento de futuro & enGauge, OCDE, Nets \\
\cline { 2 - 3 } & Pensamiento creativo & Todos \\
\cline { 2 - 3 } & Pensamiento crítico & Todos \\
\hline
\end{tabular}

Fuente: Elaboración y traducción propia a partir de marcos: ATCS, enGauge, Naep, Nets, OCDE, P21, Unesco, UE. *Los conceptos aparecen transversalmente, no necesariamente como competencias específicas, sino como habilidades combinadas.

La alfabetización digital es más que una suma de competencias técnicas que facilitan el uso de herramientas, software o hardware. La alfabetización digital nutrida interdisciplinariamente consolida la perspectiva tecnosocial que promueve el uso amplio, significativo e innovador de las TIC para la construcción de una sociedad equitativa, el empleo digno o la participación social, todos ellos aportan a la construcción de una sociedad de la información y el conocimiento.

\section{Discusión y conclusiones}

\subsection{Una propuesta de meta-marco para una alfabetización digital multidimensional}

La imagen (2) muestra, a manera de síntesis, la estructura de una propuesta de meta-marco de la alfabetización digital, el cual está conformado por un total de nueve competencias y 53 habilidades. En el Anexo (3) se recogen con detalle las definiciones de las competencias identificadas en los frameworks y en investigaciones relacionadas.

El meta-marco contempla tres competencias directas: 1) información y datos, 2) técnica y 3) comunicación y colaboración; y cinco transversales: 1) pensamiento crítico, 2) pensamiento creativo, 3) pensamiento de futuro, 4) interpersonal y 5) ciudadanía global y conciencia multicultural. Las competencias directas (señaladas con la letra D) se refieren a competencias lineales que son aportes directos desde los campos de la alfabetización informacional, alfabetización mediática, alfabetización TIC y alfabetización tecnológica, es decir todas las alfabetizaciones integradas en el concepto alfabetización digital. Las competencias transversales (identificadas con la letra T) son todas aquellas que cumplen un rol complementario.

Las competencias directas y transversales interactúan entre sí. A manera de ejemplo, para entender ambas tipologías, cuando un usuario decide usar una herramienta (competencia directa: tecnológica) evalúa la seguridad de sus datos en la herramienta (competencia transversal: pensamiento crítico) y hace un manejo efectivo de su identidad digital en dicha herramienta (competencia transversal: interpersonal). Es decir, pone en práctica habilidades directas y transversales, que superan el enfoque técnico, en cada experiencia. Todo esto nos lleva a considerar un enfoque multidimensional de la alfabetización digital con el fin de no "reducir la competencia digital a su dimensión más tecnológica e instrumental" (Gutiérrez \& Tyner, 2012). 
Siguiendo las dimensiones de la alfabetización digital identificadas por Martínez-Bravo, Sádaba, Serrano-Puche (2020), en el meta-marco propuesto las competencias se plasman en seis categorías de dimensiones, como grandes áreas donde confluyen las competencias. La dimensión cognitiva integra competencias de alto orden como la resolución de problemas, el desarrollo del razonamiento lógico, procesos como el análisis, la interpretación, la creatividad, la producción, etc. La dimensión operativa tiene un enfoque instrumental e implica, entre otros, habilidades para el uso de herramientas o la resolución de problemas técnicos. La dimensión crítica abarca actitudes y valores, el uso crítico de la información y las herramientas. La dimensión social integra el sentido de pertenencia a una comunidad global, la participación en redes y la comunicación en el ecosistema digital. La dimensión emocional está enfocada en la gestión de las emociones y la construcción de relaciones saludables. Finalmente, la dimensión proyectiva, abarca la conciencia de habitar entornos complejos y cambiantes, la actitud de adquirir conocimiento para hacer predicciones, generar respuestas anticipadas y resolver problemas a partir de tecnologías innovadoras.

Existe una conexión directa y consistente entre la dimensión, la competencia y la habilidad. Las 53 habilidades se despliegan en el Anexo (4) con las definiciones localizadas en los distintos frameworks. 
RLCS, Revista Latina de Comunicación Social, 79, 76-110

[Investigación] DOI: 10.4185/RLCS-2021-1508| ISSN 1138-5820| Año 2021

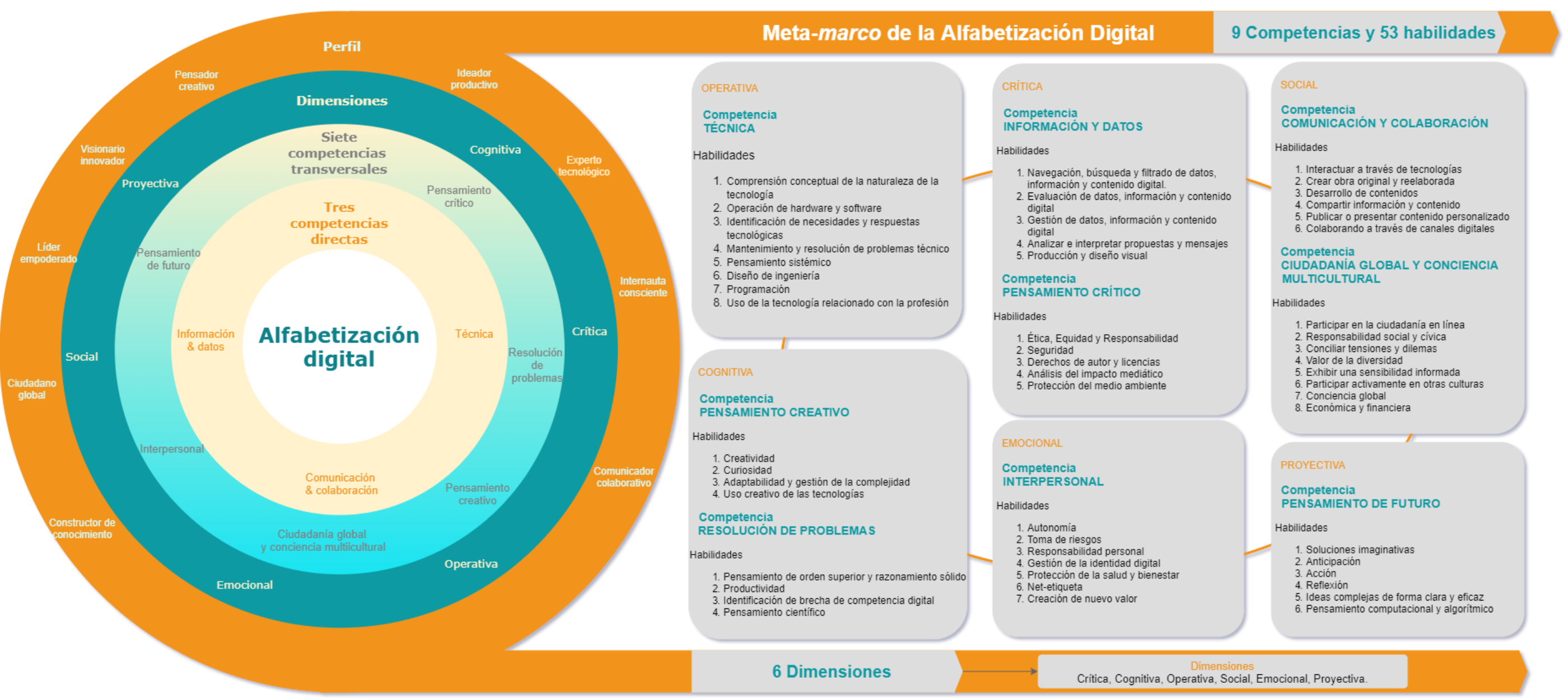

Imagen 2: Propuesta de meta-marco de la alfabetización digital

Fuente: Elaboración propia integrando los marcos de competencias del siglo XXI: ATCS, enGauge, Naep, Nets, OCDE, P21, Unesco, UE. El

*El Anexo 3 expone una versión detallada con definiciones de la propuesta de meta-marco, así como su interrelación entre perfil, dimensión, tipo de competencia, competencia y habilidad. 
Si bien no existe un acuerdo para el uso del término alfabetización digital (Gallardo-Echanique et al. 2015; Ilomäki et al., 2016; Siddiq; Gochyyev; Wilson, 2017; Chu et al., 2017), este meta-marco adopta este término ya que ha sido señalado como un concepto que integra diversas alfabetizaciones relacionadas, tanto en los frameworks estudiados, especialmente en los más actuales, como en otras investigaciones (Ferrari, 2012; Van-Laar et al., 2017; Unesco, 2018; Pérez-Escoda, García-Ruiz y Aguaded, 2019; Martínez-Bravo, Sádaba, Serrano-Puche, 2020).

Esta propuesta de meta-marco recoge ocho visiones, que a su vez tienen diferentes énfasis en múltiples alfabetizaciones, lo que permite llegar a un nivel detallado del alcance de las competencias y habilidades y, por lo tanto, comprender el radio de impacto de cada una y sus implicaciones, lo que favorece a la implementación de ecosistemas de implementación y sistemas de evaluación.

El desarrollo de las competencias digitales identificadas en esta propuesta busca desplegar un perfil más crítico y reflexivo que consolide al aprendiz como: un pensador creativo, constructor del conocimiento, ideador productivo, experto tecnológico, internauta consciente, comunicador colaborativo, visionario innovador, ciudadano global y un líder empoderado, a través del uso responsable y significativo de las tecnologías.

\subsection{Contribución de la alfabetización digital a la Agenda 2030, los derechos humanos y el bienestar común}

El enfoque holístico y humanista de la competencia digital es una visión compartida en los marcos de referencia de competencias del siglo XXI, donde se promueve el uso de las TIC de forma efectiva, eficiente, apropiada, crítica, creativa, autónoma, flexible, ética y reflexiva.

A manera de consenso entre los diferentes frameworks la alfabetización digital multidimensional se puede sintetizar en seis ideas claves:

1. Estar alfabetizado en el siglo XXI requiere la capacidad de leer, interpretar, dar significado y comunicarse en el ecosistema digital.

2. La competencia digital es una competencia central y base fundamental en los marcos de competencias del siglo XXI.

3. La alfabetización digital es un concepto convergente de diferentes enfoques, que cubre muchas áreas y alfabetizaciones.

4. Es el conjunto de conocimientos, habilidades, actitudes y valores.

5. Implica el uso seguro, crítico, eficaz, eficiente, apropiado, creativo, autónomo, flexible, ético, reflexivo de las TIC y los medios, herramientas y plataformas digitales.

6. Favorece la participación en sociedad, el desarrollo personal, profesional y el empoderamiento en la vida diaria, aportando a la construcción de una sociedad equitativa.

Cabe resaltar que la alfabetización tradicional es la vía de entrada a la alfabetización digital, por lo cual el mejoramiento del sistema actual y la cobertura de la educación inicial, básica y secundaria sigue siendo un desafío fundamental.

Es importante también apuntar que la alfabetización digital y el uso significativo de las TIC tiene una gran conexión con los Objetivos de Desarrollo Sostenible, no solo porque impulsa la innovación social, tecnológica y científica, sino porque también consolida espacios que contribuyen al progreso de los objetivos (Porcelli, 2020) y de la protección de derechos humanos (Ferrari, 2012). Así también, entre las habilidades de la competencia digital se señala el uso sostenible de las tecnologías, las responsabilidades éticas con el planeta y las personas, la innovación, el empoderamiento social, personal y laboral, los cuales se relacionan con la visión de la Agenda 2030. 
Por su parte, un tema a considerarse en las propuestas con respecto a la implementación de las competencias del siglo XXI, en particular de la competencia digital, es generar mecanismos y guías que garanticen el desarrollo de estas más allá del entorno de aprendizaje formal y los públicos infantiles o adolescentes (Pessoa, 2015). Gran parte de las iniciativas consideran el entorno de los centros educativos, lo cual muchas veces conduce a una implementación gubernamental que se queda reducida en este contexto, generando una brecha digital generacional y social (Busquet-Duran, Medina-Cambrón y Ballano-Macías, 2013).

Sin duda, uno de los propósitos más importantes de la alfabetización digital es precisamente cerrar la brecha digital para una participación en igualdad de condiciones. Si bien en una era digital la alfabetización tradicional no basta, ambas (tradicional y digital) son indispensables para vivir, trabajar y participar en la sociedad actual.

Finalmente, conviene reflexionar sobre el adjetivo digital de la alfabetización. Los conceptos siguen evolucionando y frente a la visión tradicional del leer y escribir, el siglo XXI exige una nueva forma de lectura y escritura a través de herramientas y tecnologías en un ecosistema de internet. Por lo tanto, más que pensar en el concepto alfabetización digital podríamos hablar de una alfabetización en la era digital.

\section{Bibliografía}

Ala-Mutka, K., Punie, Y. y Redecker, C. (2007). Key Competences for Lifelong Learning: European Reference Framework. European Commission. Luxembourg

Ananiadou, K. \& Claro, M. (2009). $21^{\text {st }}$ Century Skills and Competences for New Millennium Learners in OECD Countries. OECD Education Working Papers. https://doi.org/10.1787/218525261154

Lang, B., Dolan, R., Kemper, J. \& Northey, G. (2020). Prosumers in times of crisis: definition, archetypes and implications. Journal of Service Management, 32(2), 176-189. DOI 10.1108/JOSM-05-2020-0155

Busquet-Duran, J., Medina-Cambrón, A., \& Ballano-Macías, S. (2013). El uso de las TRIC y el choque cultural en la escuela. Encuentros y desencuentros entre maestros y alumnos. Mediterranean Journal of Communication / Revista Mediterránea de Comunicación, 4(2), 115135.

Carballo, M., López-Escobar, E. \& McCombs, M. (2018). Communication, Public Opinion, and Democracy: New Challenges. Communication \& Society, 31(4), 121-134. https://doi.org/10.15581/003.31.4.121-133

Chu, S.K.W., Reynolds, R.B., Tavares, N.J., Notaria, M. \& Lee, C.W.Y. (2017). Twenty-First Century Skills and Global Education Roadmaps $21^{\text {st }}$ Century Skills. In Development Through Inquiry-Based Learning from theory to practice (pp. 17-32). Springer Singapore. https://doi.org/10.1007/978-981-10-2481-8_2

Cortoni, I., LoPresti, V., \& Cervelli, P. (2015). Digital Competence Assessment: A Proposal for Operationalizing the Critical Dimension. Journal of Media Literacy Education, 7(1), 46-57. 
Coventry, L., \& Branley, D. (2018). Cybersecurity in healthcare: A narrative review of trends, threats and ways forward. Maturitas, 113, 48-52. https://doi.org/10.1016/j.maturitas.2018.04.008

Dede, C. (2010). Comparing Frameworks for “21st Century Skills”. En J. Bellanca \& R. Brandt (Eds.). 21st Century Skills: Rethinking How Students Learn. Bloomington. Solution Tree Press, $51-75 . \quad$ Recuperado de http://sttechnology.pbworks.com/f/Dede_(2010)_Comparing\%20Frameworks\%20for\%2021st\%2 0Century\%20Skills.pdf

Fernández-Villanueva, C. \& Bayarri Toscano, G. (2021). Legitimation of hate and political violence through memetic images: the Bolsonaro campaign. Communication \& Society, 34(2), 449-468. Doi: $10.15581 / 003.34 .2 .449-468$

Ferrari, A. (2012). DIGCOMP: Digital Competence in Practice. An Analysis of Frameworks. (Technical Report). Joint Research Centre of the European Commission.

Ferrari, A. (2013). DIGCOMP: A Framework for Developing and Understanding Digital Competence in Europe. European Commission. https://bit.ly/3cSgRhK

Ferrés, J., Masanet, M.J. \& Mateus, J.C., (2018). "Three paradoxes in the approach to educational technology in the education studies of the Spanish universities". International journal of educational technology in higher education, v. 5, art. 15. https://doi.org/10.1186/s41239-018$\underline{0097-y}$

Franganillo, Jorge (2020). "Lifelogging: el fenómeno de las 'cajas negras' personales”. Anuario ThinkEPI, v. 14, e14f02. https://doi.org/10.3145/thinkepi.2020.e14f02

Gallardo-Echenique, E., Minelli-de-Oliveira., Marqués-Molias, L. \& Esteve-Mon, F. (2015). "Digital competence in the knowledge society". Journal of online learning \& teaching, v. 11, n. 1, pp. 116. https://jolt.merlot.org/vol11no1/Gallardo-Echenique_0315.pdf

García-Pérez, L., García-Garnica, M., \& Olmedo-Moreno, E. M. (2021). Skills for a Working Future: How to Bring about Professional Success from the Educational Setting. Education Sciences, 11(1), 27. https://doi.org/10.3390/educsci11010027

Gómez Díaz de León, C. \& León de la Garza, E. A. (2014). Método comparativo. In: Métodos y técnicas cualitativas y cuantitativas aplicables a la investigación en ciencias sociales. Tirant Humanidades México, pp. 223-251. ISBN 9788416062324

Gutiérrez, A. \&Tyner, K. (2012). Educación para los medios, alfabetización mediática y competencia digital. Comunicar, 19 (38), 31-39. https://doi.org/10.3916/c38-2012-02-03

Jenkins, H. (2006). Convergence Culture: La cultura de la convergencia de los medios de comunicación. Ediciones Paidós Ibérica.

Kingsinger, P. \& Walch, K. (2012). Living and leading in a VUCA world. Thunderbird University. 
Ilomäki, L., Paavola, S., Lakkala, M. \& Kantosalo, A. (2016). Digital competence - an emergent boundary concept for policy and educational research. Education and information technologies, v. 21, n. 3, pp. 655-679. https://doi.org/10.1007/s10639-014-9346-4

Martínez-Bravo, M.C., Sádaba-Chalezquer, C. \& Serrano-Puche, J. (2020). Fifty years of digital literacy studies: A meta-research for interdisciplinary and conceptual convergence. Profesional de la información, v. 29, n. 4, e290428. https://doi.org/10.3145/epi.2020.jul.28

Martínez-Bravo, M.C., Sádaba-Chalezquer, C. \& Serrano-Puche, J. (2020). Dimensiones de la alfabetización digital en los marcos de competencias del Siglo XXI. En: Aguaded, I \& VizcaínoVerdú, A. (Eds.), Redes Sociales y Ciudadanía: hacia un mundo ciberconectado y empoderado. pp. 735-744. Grupo Comunicar Ediciones. ISBN: 978-84-937316-6-3. DOI: https://doi.org/10.3916/Alfamed2020.

Meshcheryakova, M. A., Shalnev, O. G. \& Filatova, M. V. (2020). Strategies for Developing Universal Skills for the VUCA World. Vestnik Voronežskogo Gosudarstvennogo Universiteta Inženernyh Tehnologij, 82(3), 279-283. https://doi.org/10.20914/2310-1202-2020-3-279-283

Moreno, A. (2019). El bitcoin como medio de intercambio y los retos que representa para la regulación financiera peruana. International Journal of Digital and Data Law; Vol. 5. 89-102.

Moya Otero, J \& Tiana, A. (2010). Las competencias básicas: un nuevo perfil educativo para el siglo XXI. Ministerio de Educación, Cultura y Deporte. Gobierno de España. Recuperado de http://cefire.edu.gva.es/pluginfile.php/573257/mod_resource/content/1/Modulo1.pdf

New Media Consortium. (2017). 2017 Digital Literacy Impact Study. An NMC Horizon Project Strategic Brief. Volume 3.5. In New Media Consortium. New Media Consortium. Recuperado de https://www.learntechlib.org/p/182080/

North Central Regional Educational Laboratory (NCRL) and Metiri Group. (2003). EnGauge $21^{\text {st }}$ century skills: Literacy in the Digital Age. Available online at: http://www.metiri.com/21/MetiriNCREL21stSkills.pdf

Organisation for Economic Co-operation and Development (OECD). (2019). The Future of Education and Skills, Education 2030. Paris: OCDE. https://doi.org/10.1787/trends_edu-2019-en.

Pangrazio, L., \& Sefton-Green, J. (2021). Digital Rights, Digital Citizenship and Digital Literacy: What's the Difference? Journal of New Approaches in Educational Research, 10(1), 1527.Pedrioli, C. A. (2020). Regulating Online Hate Speech: A U.S. Perspective. International Journal of Digital and Data Law. 259 (2020), Available at: https://ssrn.com/abstract=3578418

Pérez-Escoda, A., García-Ruiz, R. \& Aguaded, I. (2019). Dimensions of digital literacy in five models of development [Dimensiones de la alfabetización digital a partir de cinco modelos de desarrollo]. $\quad$ Cultura $\quad y \quad$ Educación, $\quad 31(2), \quad 232-266$. https://doi.org/10.1080/11356405.2019.1603274

Pessoa, T. (2015). Aprendizaje informal, alfabetización mediática e inclusión social. Descripción de una experiencia. Profesorado: Revista de Curriculum y Formación Del Profesorado, 19(2), 7591. http://www.ugr.es/ recfpro/rev192ART5.pdf 
Porcelli, A. M. (2020). El valor de las redes sociales en el progreso de los objetivos de desarrollo sostenible: The value of social networks in the progress of sustainable development goals. Lex Social: Revista de Los Derechos Sociales, 10(. 2), 595-630. https://doi.org/10.46661/lexsocial.5078

Rheingold, H. (1996). La comunidad virtual. Una sociedad sin fronteras. Barcelona: Editorial Gedisa S.A.

Reig Hernández, D. (2016). TIC, TAC, TEP internet como escuela de vida. Cuadernos de pedagogía, 473, 24-27.

Salaverría, R., Buslón, N., López-Pan, F., León, B., López-Goñi, I \& Erviti, M.C. (2020). "Desinformación en tiempos de pandemia: tipología de los bulos sobre la Covid-19". El profesional de la información, v. 29, n. 3, e290315. https://doi.org/10.3145/epi.2020.may.15

Selke, S. (2016). Lifelogging. Digital Self-Tracking and Lifelogging - between Disruptive Technology and Cultural Transformation. Disruptive Technology and Cultural TransformationThe Impact of a Societal Phenomenon. Springer Ebooks. Springer Fachmedien Wiesbaden

Shek, D. T. L., Yu, L. \& Siu, A. M. H. (2015). Interpersonal Competence and Service Leadership. International Journal on Disability and Human Development, v. 14, no. 3, p. 265-274. https://doi.org/10.1515/ijdhd-2015-0407

Siddiq, F., Gochyyev, P. \& Wilson, M. (2017). Learning in digital networks - ICT literacy: A novel assessment of students' 21st century skills. Computers and Education, v. 109, pp. 11-37. https://doi.org/10.1016/j.compedu.2017.01.014

Toffler, A. (1980). The Third Wave. Vol. 484, Bantam books, New York, NY.

Trujillo-Segoviano, J. (2014). El enfoque en competencias y la mejora de la educación. Ra Ximhai, vol. 10, núm. 5, julio-diciembre, pp. 307-322. https://www.redalyc.org/pdf/461/46132134026.pdf

United Nations Educational, Scientific and Cultural Organization. UNESCO. (2018). A Global Framework of Reference on Digital Literacy Skills for Indicator 4.4.2. Disponible en http://uis.unesco.org/sites/default/files/documents/ip51-global-framework-reference-digitalliteracy-skills-2018-en.pdf

United Nations Educational, Scientific and Cultural Organization. UNESCO. (2017). E2030: Educación y Habilidades para el Siglo 21. Documento de trabajo. Recuperado de http://www.unesco.org/new/fileadmin/MULTIMEDIA/FIELD/Santiago/pdf/Habilidades-SXXIBuenos-Aires-Spa.pdf

Van-Deursen, Alexander J. A. M. (2012). "Internet skill-related problems in accessing online health information". International journal of medical informatics, v. 81, n. 1, pp. 61-72. https://doi.org/10.1016/j.ijmedinf.2011.10.005

Van-Deursen, Alexander J. A. M.; Van-Dijk, Jan A. G. M. (2014). "The digital divide shifts to differences in usage". New media \& society, v. 16, n. 3, pp. 507-526. https://doi.org/10.1177/1461444813487959 
Van-Laar, E., Van-Deursen, J. A. M., Van-Dijk, A. G. M. \& De-Haan, J. (2017). The relation between $21^{\text {st }}$-century skills and digital skills: A systematic literature review. Computers in Human Behavior, v. 72, pp. 577-588. https://doi.org/10.1016/j.chb.2017.03.010.

Villaroel, G (2001). El método comparativo: entre complejidad y generalización. Revista Venezolana de Ciencia Política. v.20 (jul-dic2001) pp. 97-120

Voogt, J. \& Roblin, N. (2012). A comparative analysis of international frameworks for 21 st century competences: Implications for national curriculum policies. Journal of Curriculum Studies, 44(3), 299-321. https://doi.org/10.1080/00220272.2012.668938

\section{AUTORES}

\section{María Cristina Martínez-Bravo}

Doctoranda en Comunicación y Máster de Investigación en Comunicación por la Universidad de Navarra. Comunicadora Social de la Pontificia Universidad Católica del Ecuador. Ha sido docente universitaria de grado y posgrado en la Universidad de las Américas y Universidad UTE (Ecuador) en cátedras del área de comunicación, periodismo y marketing. Miembro de la Red de Investigación de Conocimiento, Hardward y Software Libre (RICHSL), Activista del conocimiento libre y compartido. Algunas de sus líneas de investigación son: la alfabetización digital, la cultura digital y las Tecnologías de la Información y Comunicación para el desarrollo.

mb.macristina@gmail.com

Índice $\mathrm{H}: 2$

Orcid ID: http://orcid.org/0000-0002-8725-3267

Google Scholar: https://scholar.google.com/citations?user=9Qa59mwAAAAJ\&hl=es

ResearchGate: https://www.researchgate.net/profile/Maria-Cristina-Martinez

Academia.edu: https://unav.academia.edu/MaríaCristinaMartínezBravo

\section{Charo Sádaba}

Es Profesora Titular en la Facultad de Comunicación de la Universidad de Navarra. Desde el año 2000 investiga la relación de niños, niñas y adolescentes con la tecnología. Ha participado en numerosos proyectos de investigación competitivos a nivel nacional e internacional, entre los que destaca POSCON, una acción temática que buscaba establecer las bases para la creación de espacios seguros y positivos para los menores online. También formó parte del proyecto Generaciones Interactivas, impulsado por Telefónica Internacional entre 2007 y 2012, que encuestó a más de 200.000 menores en nueve países. Es experta independiente del programa Safer Internet de la Unión Europea.

csadaba@unav.es

Índice H: 26

Orcid ID: http://orcid.org/0000-0003-2596-2794

Google Scholar: https://scholar.google.com/citations?user=hxHbaN0AAAAJ\&hl=es

ResearchGate: https://www.researchgate.net/profile/Charo-Sadaba

Academia.edu: https://unav.academia.edu/CharoSadaba

Scopus ID: 6506571150

ResearcherID: H-3121-2015

\section{Javier Serrano-Puche}

Profesor Titular de Periodismo en la Facultad de Comunicación de la Universidad de Navarra, donde ocupa el cargo de Vicedecano de Ordenación Académica. Es investigador colaborador del Center for Internet Studies and Digital Life y del Instituto Cultura y Sociedad, de la Universidad de Navarra. Su 
producción científica más reciente se centra en las tendencias en el consumo de noticias, la desinformación en el espacio público digital y en la relación entre los medios de comunicación y las emociones. Sobre estas cuestiones ha publicado en revistas como International Journal of Communication, Media and Communication, Journal of Iberian and Latin American Research, Communications, Comunicar, o en editoriales como Routledge, Palgrave Macmillan, Springer e IGI Global.

jserrano@unav.es

Índice H: 14

Orcid ID: http://orcid.org/0000-0001-6633-5303

Google Scholar: https://scholar.google.com/citations?user=xcKzg14AAAAJ\&hl=es

ResearchGate: https://www.researchgate.net/profile/Javier-Serrano-Puche

Academia.edu: https://unav.academia.edu/JavierSerranoPuche

Scopus ID: 55249953400

ResearcherID: I-6590-2016 


\section{Anexos}

Anexo 1. Revisión exploratoria de documentos de los marcos de competencia del Siglo XXI

\begin{tabular}{|c|c|c|c|c|}
\hline $\mathbf{N}^{\circ}$ & Documento & Autor/es & Framework & Año \\
\hline 1 & Assessment and Teaching of $21^{\text {st }}$ Century Skills & $\begin{array}{l}\text { Esther Care, Patrick Griffin, Mark Wilson. } \\
\text { Editors }\end{array}$ & ATCS & 2018 \\
\hline 2 & $\begin{array}{l}\text { Assessment and Teaching of } 21^{\text {st }} \text { Century Skills: } \\
\text { Collaborative } \\
\begin{array}{l}\text { Problem } \\
\text { Progressions }\end{array}\end{array}$ & ATCS & ATCS & 2014 \\
\hline 3 & $\begin{array}{l}\text { Competencias del siglo XXI: Guía práctica para } \\
\text { promover su Aprendizaje y evaluación. Capítulo } \\
\text { latinoamericano del proyecto atc } 21 \mathrm{~s}\end{array}$ & $\begin{array}{l}\text { Fundación Omar Dengo. María Eugenia } \\
\text { Bujanda Bujanda, Valeria Ruiz González, } \\
\text { Andrea Molina Ovares, Sofía Quesada } \\
\text { Montano }\end{array}$ & ATCS & 2014 \\
\hline 4 & $\begin{array}{l}\text { Introductory module: An introduction } \\
\text { assessment and teaching of } 21^{\text {st }} \text { century skills }\end{array}$ & Patrick Griffin & ATCS & 2013 \\
\hline 5 & $\begin{array}{l}\text { Module 1: Using a developmental model to assess } \\
\text { student learning. Developmental learning } \\
\text { frameworks }\end{array}$ & $\begin{array}{l}\text { Patrick Griffin, Kerry } \text { Woods, Roz } \\
\text { Mountain, Claire Scoular }\end{array}$ & ATCS & 2013 \\
\hline 6 & Module 2: defining and assessing $21^{\text {st }}$ century skills & $\begin{array}{l}\text { Esther Care, Patrick Griffin, Kerry Woods, } \\
\text { Roz Mountain }\end{array}$ & ATCS & 2013 \\
\hline 7 & $\begin{array}{l}\text { Module 3: Atc21s collaborative problem-solving } \\
\text { assessments }\end{array}$ & Claire Scoular, Nafisa Awwal & ATCS & 2013 \\
\hline 8 & $\begin{array}{l}\text { Module 4: Use of a developmental framework for } \\
\text { teaching }\end{array}$ & $\begin{array}{l}\text { Kerry Woods, Roz Mountain, Patrick } \\
\text { Griffin, Claire Scoular }\end{array}$ & ATCS & 2013 \\
\hline 9 & Module 5: Teaching and learning $21^{\text {st }}$ century skills & $\begin{array}{l}\text { Roz Mountain, Esther Care, Claire Scoular, } \\
\text { Kerry Woods }\end{array}$ & ATCS & 2013 \\
\hline 10 & $\begin{array}{l}\text { Technology and Engineering Literacy Assessment } \\
\text { and Item Specifications } \\
\text { for the } 2014 \text { National Assessment of Educational } \\
\text { Progress. Pre-Publication Edition }\end{array}$ & $\begin{array}{l}\text { Developed by WestEd under contract to the } \\
\text { National Assessment Governing Board }\end{array}$ & NAEP & 2014 \\
\hline 11 & $\begin{array}{l}\text { Technology and Engineering Literacy Framework } \\
\text { for the } 2018 \text { National Assessment of Educational } \\
\text { Progress }\end{array}$ & $\begin{array}{l}\text { Developed for the National Assessment } \\
\text { Governing Board }\end{array}$ & NAEP & 2018 \\
\hline 12 & $\begin{array}{l}\text { A History of NAEP Assessment Frameworks. } \\
\text { Paper Commissioned for the } 20^{\text {th }} \text { Anniversary of } \\
\text { the National Assessment Governing Board 1988- } \\
2008\end{array}$ & Carol Jago & NAEP & 2009 \\
\hline 13 & $\begin{array}{l}\begin{array}{l}\text { National Assessment of } \\
\text { (NAEP) }\end{array} \\
\text { (NAucational Progress } \\
\end{array}$ & NAEP & NAEP & 2012 \\
\hline 14 & Profile for Technology (ICT) Literate Students & $\begin{array}{l}\text { International Society for Technology in } \\
\text { Education (ISTE) }\end{array}$ & NETS & 2007 \\
\hline 15 & ISTE Standards Coaches & $\begin{array}{l}\text { International Society for Technology in } \\
\text { Education (ISTE) }\end{array}$ & NETS & 2011 \\
\hline 16 & ISTE Standards Students & $\begin{array}{l}\text { International Society for Technology in } \\
\text { Education (ISTE) }\end{array}$ & NETS & 2007 \\
\hline 17 & ISTE Standards Teachers & $\begin{array}{l}\text { International Society for Technology in } \\
\text { Education (ISTE) }\end{array}$ & NETS & 2008 \\
\hline 18 & 2016 ISTE Standards for Students & $\begin{array}{l}\text { International Society for Technology in } \\
\text { Education (ISTE) }\end{array}$ & NETS & 2016 \\
\hline 19 & $\begin{array}{l}\text { A Constructivist Approach to the National } \\
\text { Educational Technology Standards for Teachers. }\end{array}$ & $\begin{array}{l}\text { International Society for Technology in } \\
\text { Education (ISTE) }\end{array}$ & NETS & 2012 \\
\hline 20 & ISTE Standards for students & $\begin{array}{l}\text { International Society for Technology in } \\
\text { Education (ISTE) }\end{array}$ & NETS & 2016 \\
\hline 21 & $\begin{array}{l}\text { Redefining learning in a technology-driven world. } \\
\text { A report to support adoption of the ISTE Standards } \\
\text { for Students }\end{array}$ & $\begin{array}{l}\text { International Society for Technology in } \\
\text { Education (ISTE) }\end{array}$ & NETS & 2016 \\
\hline 22 & ISTE Standards for educators & $\begin{array}{l}\text { International Society for Technology in } \\
\text { Education (ISTE) }\end{array}$ & NETS & 2017 \\
\hline 23 & $\begin{array}{l}\text { Future Ready LibrariansTM Framework and ISTE } \\
\text { Standards for Educators }\end{array}$ & $\begin{array}{l}\text { International Society for Technology in } \\
\text { Education (ISTE) }\end{array}$ & NETS & 2018 \\
\hline 24 & ISTE Standards for education leaders & $\begin{array}{l}\text { International Society for Technology in } \\
\text { Education (ISTE) }\end{array}$ & NETS & 2018 \\
\hline 25 & ISTE Standards for educators & International Society for Technology in & NETS & 2018 \\
\hline
\end{tabular}


RLCS, Revista Latina de Comunicación Social, 79, 76-110

[Investigación] DOI: 10.4185/RLCS-2021-1508| ISSN 1138-5820| Año 2021

\begin{tabular}{|c|c|c|c|c|}
\hline & & Education (ISTE) & & \\
\hline 26 & $\begin{array}{l}21^{\text {st }} \text { Century Skills Early Learning Framework } \\
(\mathrm{P} 21 \mathrm{ELF})\end{array}$ & Lee A. Scott / P21 & $\mathrm{P} 21$ & 2017 \\
\hline 27 & Framework for $21^{\text {st }}$ Century Learning (Brief) & Partnership for $21^{\text {st }}$ Century Learning, P21 & $\mathrm{P} 21$ & 2016 \\
\hline 28 & $\begin{array}{l}\text { Framework for } 21^{\text {st }} \text { Century Learning. A unified } \\
\text { vision for learning to ensure student success in a } \\
\text { world where change is constant and learning never } \\
\text { stops. }\end{array}$ & Battelle for Kids & $\mathrm{P} 21$ & 2019 \\
\hline 29 & P21 Framework Definitions & Partnership for $21^{\text {st }}$ Century Learning, P21 & $\mathrm{P} 21$ & 2015 \\
\hline 30 & Framework for $21^{\text {st }}$ century learning. Definitions & Battelle for Kids & $\mathrm{P} 21$ & 2019 \\
\hline 31 & $\begin{array}{l}21^{\text {st }} \text { Century Learning for Early Childhood } \\
\text { Framework }\end{array}$ & Battelle for Kids & $\mathrm{P} 21$ & 2019 \\
\hline 32 & $21^{\text {st }}$ Century Learning for Early Childhood Guide & Battelle for Kids & $\mathrm{P} 21$ & 2019 \\
\hline 33 & $\begin{array}{l}\text { Digital Competence in Practice: An Analysis of } \\
\text { Frameworks }\end{array}$ & 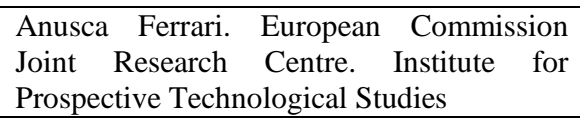 & $\begin{array}{l}\text { European } \\
\text { Union }\end{array}$ & 2012 \\
\hline 34 & $\begin{array}{l}\text { DIGCOMP: A Framework for Developing and } \\
\text { Understanding Digital Competence in Europe }\end{array}$ & $\begin{array}{l}\text { Anusca Ferrari Editors: Yves Punie and } \\
\text { Barbara N. Brečko. European Commission } \\
\text { Joint Research Centre. Institute for } \\
\text { Prospective Technological Studies }\end{array}$ & $\begin{array}{l}\text { European } \\
\text { Union }\end{array}$ & 2013 \\
\hline 35 & $\begin{array}{l}\text { A common European } \\
\text { Framework for Citizens }\end{array}$ & European Commision & $\begin{array}{l}\text { European } \\
\text { Union }\end{array}$ & 2006 \\
\hline 36 & $\begin{array}{l}\text { Digital Competence for Lifelong Learning. Policy } \\
\text { Brief }\end{array}$ & $\begin{array}{l}\text { Kirsti Ala-Mutka, Yves Punie and Christine } \\
\text { Redecker. European Commission Joint } \\
\text { Research Centre. Institute for Prospective } \\
\text { Technological Studies }\end{array}$ & $\begin{array}{l}\text { European } \\
\text { Union }\end{array}$ & 2008 \\
\hline 37 & $\begin{array}{l}\text { Key Competences for Lifelong Learning. European } \\
\text { Reference Framework }\end{array}$ & European Commision & $\begin{array}{l}\text { European } \\
\text { Union }\end{array}$ & 2007 \\
\hline 38 & $\begin{array}{l}\text { DigComp 2.0: The Digital Competence Framework } \\
\text { for Citizens }\end{array}$ & $\begin{array}{l}\text { Riina Vuorikari, Yves Punie, Stephanie } \\
\text { Carretero, Lieve Van den Brande }\end{array}$ & $\begin{array}{l}\text { European } \\
\text { Union }\end{array}$ & 2016 \\
\hline 39 & $\begin{array}{l}\text { DigComp 2.1: The Digital Competence Framework } \\
\text { for Citizens with eight proficiency levels and } \\
\text { examples of use. }\end{array}$ & $\begin{array}{l}\text { Carretero, S.; Vuorikari, R. and Punie. } \\
\text { European Union. }\end{array}$ & $\begin{array}{l}\text { European } \\
\text { Union }\end{array}$ & 2017 \\
\hline 40 & $\begin{array}{l}\text { European Framework for the Digital Competence } \\
\text { of Educators: DigCompEdu }\end{array}$ & $\begin{array}{l}\text { Redecker Christine. Punie Yves. European } \\
\text { Union. }\end{array}$ & $\begin{array}{l}\text { European } \\
\text { Union }\end{array}$ & 2017 \\
\hline 41 & Unesco Institute for Lifelong learning, Report 2017 & $\begin{array}{l}\text { Organización de las Naciones Unidas para } \\
\text { la Educación, la Ciencia y la Cultura. } \\
\text { UNESCO }\end{array}$ & Unesco & 2018 \\
\hline 42 & A Global measure of digital and ICT literacy skills & $\begin{array}{l}\text { Organización de las Naciones Unidas para } \\
\text { la Educación, la Ciencia y la Cultura. } \\
\text { UNESCO }\end{array}$ & Unesco & 2016 \\
\hline 43 & $\begin{array}{l}\text { A Global Framework of Reference on Digital } \\
\text { Literacy Skills for Indicator } 4.4 .2\end{array}$ & $\begin{array}{l}\text { Organización de las Naciones Unidas para } \\
\text { la Educación, la Ciencia y la Cultura. } \\
\text { UNESCO }\end{array}$ & Unesco & 2018 \\
\hline 44 & $\begin{array}{l}\text { Global Media and Information Literacy } \\
\text { Assessment Framework: Country Readiness and } \\
\text { Competencies }\end{array}$ & $\begin{array}{l}\text { Organización de las Naciones Unidas para } \\
\text { la Educación, la Ciencia y la Cultura. } \\
\text { UNESCO }\end{array}$ & Unesco & 2013 \\
\hline 45 & $\begin{array}{l}\text { Media and information literacy curriculum for } \\
\text { teachers }\end{array}$ & $\begin{array}{l}\text { Organización de las Naciones Unidas para } \\
\text { la Educación, la Ciencia y la Cultura. } \\
\text { UNESCO }\end{array}$ & Unesco & 2011 \\
\hline 46 & ICT Competency Framework for Teachers & $\begin{array}{l}\text { Organización de las Naciones Unidas para } \\
\text { la Educación, la Ciencia y la Cultura. } \\
\text { UNESCO }\end{array}$ & Unesco & 2018 \\
\hline 47 & $\begin{array}{l}\text { enGauge } 21^{\text {st }} \text { Century Skills: Literacy in the Digital } \\
\text { Age }\end{array}$ & $\begin{array}{l}\text { North Central Regional Educational } \\
\text { Laboratory and the Metiri Group }\end{array}$ & EnGauge & 2003 \\
\hline 48 & $\begin{array}{l}\text { Projects on competencies in the OECD context: } \\
\text { Analysis of theoretical and conceptual foundations }\end{array}$ & $\begin{array}{l}\text { L.H. Salganik, D.S. Rychen, U. Moser and } \\
\text { J. Konstant }\end{array}$ & OCDE & 1999 \\
\hline 49 & Defining and selecting key competencies & D.S. Rychen and L.H. Salganik (eds.) & OCDE & 2001 \\
\hline 50 & $\begin{array}{l}\text { Key competencies for a successful life and a well- } \\
\text { functioning society }\end{array}$ & D.S. Rychen and L.H. Salganik (eds.) & OCDE & 2003 \\
\hline 51 & $\begin{array}{l}\text { Las competencias clave para el bienestar personal, } \\
\text { económico y social. }\end{array}$ & $\begin{array}{l}\text { Comp. Dominique Simona Rychen y Laura } \\
\text { Hersh Salganik. }\end{array}$ & OCDE & 2006 \\
\hline 52 & $\begin{array}{l}\text { E2030 Conceptual framework: key competencies } \\
\text { for } 2030 \text { (DeSeCo 2.0) }\end{array}$ & Miho Taguma, Dominique Simona Rychen & OCDE & 2016 \\
\hline 53 & Future of education and skills 2030: reflections on & Miho Taguma, Lars Barteit & OCDE & 2017 \\
\hline
\end{tabular}


RLCS, Revista Latina de Comunicación Social, 79, 76-110

[Investigación] DOI: 10.4185/RLCS-2021-1508| ISSN 1138-5820| Año 2021

\begin{tabular}{|c|c|c|c|c|}
\hline & Transformative competencies 2030 & & & \\
\hline 54 & $\begin{array}{l}\text { Trends Analysis. Future Shocks and Shifts: } \\
\text { Challenges for the Global Workforce and Skills } \\
\text { Development. OECD EDUCATION 2030, } \\
\text { first informal working group webinar/meeting }\end{array}$ & Miho Taguma, Katja Anger & OCDE & 2017 \\
\hline 55 & $\begin{array}{l}\text { Education } 2030 \text { - Conceptual learning framework: } \\
\text { Background papers. The Future of Education and } \\
\text { Skills: Education 2030. 6th Informal Working } \\
\text { Group (IWG) meeting }\end{array}$ & $\begin{array}{l}\text { Miho Taguma, Lars Barteit, Meow Hwee } \\
\text { LIM }\end{array}$ & OCDE & 2017 \\
\hline 56 & $\begin{array}{l}\text { Future of Education and Skills 2030: Curriculum } \\
\text { Analysis. Preparing humanity for change and } \\
\text { artificial intelligence: Learning to learn as a } \\
\text { safeguard against volatility, uncertainty, } \\
\text { complexity and ambiguity }\end{array}$ & Miho Taguma, Gabriel Florence & OCDE & 2018 \\
\hline 57 & $\begin{array}{l}\text { The future of education and skills. Education } 2030 . \\
\text { Position paper. }\end{array}$ & OCDE & OCDE & 2018 \\
\hline 58 & $\begin{array}{l}\text { OECD Future of Education and Skills 2030. OECD } \\
\text { Learning Compass 2030. A series of concept notes }\end{array}$ & OCDE & OCDE & 2019 \\
\hline 59 & $\begin{array}{l}\text { OECD Future of education and skill } 2030 . \\
\text { Conceptual learning framework. Core Foundations } \\
\text { for } 2030\end{array}$ & OCDE & OCDE & 2019 \\
\hline 60 & $\begin{array}{l}\text { OECD Future of education and skill } 2030 . \\
\text { Conceptual learning framework. } \\
\text { Compass } 2030\end{array}$ & OCDE & OCDE & 2019 \\
\hline 61 & $\begin{array}{l}\text { OECD Future of education and skill } 2030 . \\
\text { Conceptual learning framework. Knowledge for } \\
2030\end{array}$ & OCDE & OCDE & 2019 \\
\hline 62 & $\begin{array}{l}\text { OECD Future of education and skill } 2030 . \\
\text { Conceptual learning framework. Transformative } \\
\text { competencies FOR } 2030 \text {. }\end{array}$ & OCDE & OCDE & 2019 \\
\hline 63 & $\begin{array}{l}\text { OECD Future of education and skill } 2030 . \\
\text { Conceptual learning framework. Skills } 2030\end{array}$ & OCDE & OCDE & 2019 \\
\hline 64 & $\begin{array}{l}\text { OECD Future of education and skill } 2030 . \\
\text { Conceptual learning framework. Attitudes and } \\
\text { Values for } 2030\end{array}$ & OCDE & OCDE & 2019 \\
\hline 65 & $\begin{array}{l}\text { OECD Future of education and skill } 2030 . \\
\text { Conceptual learning framework. Student Agency }\end{array}$ & OCDE & OCDE & 2019 \\
\hline 66 & $\begin{array}{l}\text { OECD Future of education and skill } 2030 . \\
\text { Conceptual learning framework. Anticipation- } \\
\text { Action-Reflection (AAR) Cycle }\end{array}$ & OCDE & OCDE & 2019 \\
\hline 67 & $\begin{array}{l}\text { Curriculum (re)design. A series of thematic reports } \\
\text { from the OECD Education } 2030 \text { project } \\
\text { overview brochure }\end{array}$ & OCDE & OCDE & 2020 \\
\hline 68 & Technical Report for Curriculum Redesign series & OCDE & OCDE & 2020 \\
\hline 69 & $\begin{array}{l}\text { What Students Learn Matters. Towards a 21st } \\
\text { Century Curriculum }\end{array}$ & OCDE & OCDE & 2020 \\
\hline 70 & Curriculum Overload. A Way Forward & OCDE & OCDE & 2020 \\
\hline
\end{tabular}

Fuente: Elaboración propia

Anexo 2. Modelo de ficha para recolección de información de casos.

Nombre de marco de referencia analizado

\begin{tabular}{|l|l|}
\hline Componentes comparativos & Descripción de campo \\
\hline Institución & Organización(es) que desarrollan documento \\
\hline Nombre del documento & Título de documento principal \\
\hline Año de publicación & Fecha en que ha sido compartido públicamente \\
\hline Sitio web & Url de la iniciativa \\
\hline $\begin{array}{l}\text { Número de documentos analizados de este } \\
\text { framework }\end{array}$ & $\begin{array}{l}\text { Se especifica el número de documento revisados (principales y } \\
\text { secundarios) }\end{array}$ \\
\hline Alcance & Se especifica alcance de la iniciativa: regional, nacional, internacional. \\
\hline Grupo objetivo & Personas a las que está dirigido el documento \\
\hline $\begin{array}{l}\text { Metodología usada para la construcción de este } \\
\text { framework }\end{array}$ & $\begin{array}{l}\text { Procedimientos metodológicos encaminados por las diferentes } \\
\text { iniciativas para plasmar sus propuestas }\end{array}$ \\
\hline
\end{tabular}


RLCS, Revista Latina de Comunicación Social, 79, 76-110

[Investigación] DOI: 10.4185/RLCS-2021-1508| ISSN 1138-5820| Año 2021

\begin{tabular}{|c|c|}
\hline $\begin{array}{l}\text { Trabajo relacionados } \mathrm{o} \text { integrados en esta } \\
\text { propuesta }\end{array}$ & Otro tipo de trabajos relacionados en la propuesta \\
\hline Objetivo de propuesta & Transcripción de objetivos \\
\hline Visión & Transcripción de visión \\
\hline Estructura de documento & Enumeración de la estructura general del documento \\
\hline Componentes de la propuesta de competencias & $\begin{array}{l}\text { Estructura de propuesta de competencias: dimensiones, competencias, } \\
\text { áreas, habilidades, etc. }\end{array}$ \\
\hline Enfoque de alfabetización & $\begin{array}{l}\text { Enfoque principal o nombre de la alfabetización con el que se } \\
\text { desarrolla la propuesta }\end{array}$ \\
\hline Definición alfabetización (categoría general) & Transcripción de definición \\
\hline Competencias y/o áreas específicas identificadas & Transcripción de competencias \\
\hline $\begin{array}{l}\text { ¿La propuesta tiene una guía de implementación de } \\
\text { competencias? }\end{array}$ & Se detalla sí o no \\
\hline Tipo de implementación recomendada & $\begin{array}{l}\text { Se detalla si la propuesta hace mención a algún tipo de implementación: } \\
\text { transversal o }\end{array}$ \\
\hline $\begin{array}{l}\text { ¿La propuesta tiene una guía de evaluación } \\
\text { competencias? }\end{array}$ & Se detalla sí o no \\
\hline
\end{tabular}

Fuente: Elaboración propia 
RLCS, Revista Latina de Comunicación Social, 79, 76-110

[Investigación] DOI: 10.4185/RLCS-2021-1508| ISSN 1138-5820| Año 2021

Anexo 3. Meta-marco de la alfabetización digital - Definición de competencias identificadas en los marcos estudiados

\begin{tabular}{|c|c|c|c|c|c|}
\hline Dimensión & Rol & Perfil & Competencias & Descripción & Habilidades \\
\hline \multirow[t]{2}{*}{ Cognitiva } & $\mathrm{T}$ & $\begin{array}{l}\text { Pensador } \\
\text { creativo }\end{array}$ & $\begin{array}{l}\text { Pensamiento } \\
\text { creativo }\end{array}$ & $\begin{array}{l}\text { Marco Unesco: "Uso creativo de tecnologías digitales, utilización de herramientas y tecnologías } \\
\text { digitales para crear conocimiento e innovar procesos y productos" } \\
\text { Marco NETS: "Producir artefactos creativos y crear experiencias de aprendizaje significativas" }\end{array}$ & $\begin{array}{l}\text { 1.1. Creatividad } \\
\text { 1.2. } \\
\text { 1.3. Adaptabilidad y gestión de la complejidad } \\
\text { 1.4. Innovación con herramientas digitales }\end{array}$ \\
\hline & $\mathrm{T}$ & $\begin{array}{l}\text { Ideador } \\
\text { productivo }\end{array}$ & $\begin{array}{l}\text { Resolución de } \\
\text { problemas }\end{array}$ & $\begin{array}{l}\text { Marcos Unesco y UE: "Identificar necesidades y problemas, y resolver problemas conceptuales y } \\
\text { situaciones problemáticas en entornos digitales. Utilizar herramientas digitales para innovar } \\
\text { procesos y productos. Estar al día de la evolución digital" } \\
\text { Marco ATCS: "La resolución de problemas implica ser capaz de negociar entornos y situaciones } \\
\text { complejos y que cambian dinámicamente con éxito al basarse en patrones de comportamiento para } \\
\text { alcanzar un objetivo deseado. Más específicamente, resolución de problemas dinámicos o } \\
\text { complejos se ha definido como "la interacción exitosa con entornos de tareas que son dinámicos } \\
\text { (es decir, cambian en función de la intervención del usuario y / o en función del tiempo) y en la } \\
\text { que algunas, si no todas, las regularidades del entorno solo pueden revelarse mediante la } \\
\text { exploración e integración exitosas de la información obtenida en ese proceso. Por lo tanto, alguien } \\
\text { que tiene éxito en la resolución de problemas es capaz de interactuar con el entorno de la tarea y } \\
\text { adaptarse a la naturaleza dinámica de estos entornos para para recopilar información; integrar y } \\
\text { estructurar la información de una manera significativa; y aplicar eficazmente el conocimiento } \\
\text { adquirido para hacer predicciones y resolver el problema en cuestión" }\end{array}$ & $\begin{array}{l}\begin{array}{l}\text { 2.1. Pensamiento de orden superior y } \\
\text { razonamiento }\end{array} \\
\text { 2.2. } \\
\text { 2.3. Identificación de brecha de competencia } \\
\text { digital } \\
\text { 2.4. Pensamiento científico }\end{array}$ \\
\hline Operativa & $\mathrm{D}$ & $\begin{array}{l}\text { Experto } \\
\text { tecnológico }\end{array}$ & Técnica & $\begin{array}{l}\text { Marco enGauge: "Conocimiento sobre qué es la tecnología, cómo funciona, para qué sirve y } \\
\text { cómo se puede utilizar de manera eficiente y eficaz para lograr objetivos específicos" } \\
\text { Marco NAEP: "Diseño y sistemas cubre la naturaleza de la tecnología, el proceso de diseño de } \\
\text { ingeniería mediante el cual se desarrollan las tecnologías y los principios básicos para lidiar con } \\
\text { las tecnologías cotidianas, incluido el mantenimiento y la solución de problemas. La comprensión } \\
\text { del proceso de diseño es particularmente valiosa en la evaluación de tecnologías, y también se } \\
\text { puede aplicar en áreas fuera de la tecnología, ya que el diseño es una habilidad de amplia } \\
\text { aplicación" } \\
\text { Marco Unesco: "Operación de dispositivos y software: implica identificar y utilizar herramientas } \\
\text { y tecnologías de hardware. Identificar datos, información y contenido digital necesarios para } \\
\text { operar herramientas y tecnologías de software". }\end{array}$ & 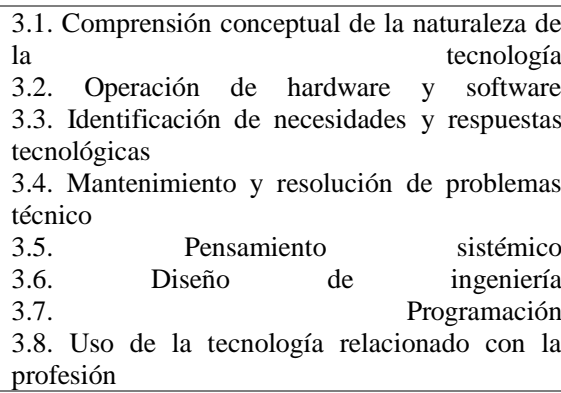 \\
\hline Crítica & $\mathrm{D}$ & $\begin{array}{l}\text { Constructor } \\
\text { de } \\
\text { conocimiento }\end{array}$ & $\begin{array}{l}\text { Información y } \\
\text { datos }\end{array}$ & $\begin{array}{l}\text { Marcos Unesco y UE: "implica articular las necesidades de información, localizar y recuperar } \\
\text { datos, información y contenido digitales. Juzgar la relevancia de la fuente y su contenido. } \\
\text { Almacenar, administrar y organizar datos, información y contenido digitales" } \\
\text { Marco enGauge: "Capacidad para evaluar información a través de una variedad de medios, } \\
\text { reconocer cuándo se necesita la información, localizar, sintetizar y utilizar la información de } \\
\text { manera eficaz y realizar estas funciones mediante la tecnología, las redes de comunicación y los } \\
\text { recursos electrónicos, evaluándolo de manera crítica y competente, y usándolo de manera precisa y } \\
\text { creativa" } \\
\text { Marco P21: "Acceso y evaluación de la información, uso y administración de la información" }\end{array}$ & $\begin{array}{l}\text { 4.1. Navegación, búsqueda y filtrado de datos, } \\
\text { información y contenido digital. } \\
\text { 4.2. Evaluación de datos, información y } \\
\text { contenido } \\
\text { 4.3. Gestión de datos, información y contenido } \\
\text { digital } \\
\text { 4.4. Analizar e interpretar propuestas y mensajes } \\
\text { 4.5. Producción y diseño visual }\end{array}$ \\
\hline
\end{tabular}


RLCS, Revista Latina de Comunicación Social, 79, 76-110

[Investigación] DOI: 10.4185/RLCS-2021-1508| ISSN 1138-5820| Año 2021

\begin{tabular}{|c|c|c|c|c|c|}
\hline Dimensión & Rol & Perfil & Competencias & Descripción & Habilidades \\
\hline & $\mathrm{T}$ & $\begin{array}{l}\text { Internauta } \\
\text { consciente }\end{array}$ & $\begin{array}{l}\text { Pensamiento } \\
\text { crítico }\end{array}$ & $\begin{array}{l}\text { Marco NAEP: Conciencia de efectos que la tecnología tiene en la sociedad y el mundo natural y } \\
\text { con el tipo de cuestiones éticas que surgen de esos efectos. } \\
\text { Marco OCDE: "El pensamiento crítico se puede utilizar cuando uno reflexiona sobre sus acciones } \\
\text { y las acciones de otros". } \\
\text { Cortoni, LoPresti \& Cervelli (2015). "La competencia crítica es la capacidad de analizar y } \\
\text { razonar de manera autónoma sobre la lógica, la naturaleza y contenido de los mensajes, así como } \\
\text { la interpretación de los símbolos, códigos y convenciones culturales utilizados por los medios" } \\
\text { Ala-Mutka, Punie y Redecker (2007) El uso crítico de las TIC incluye el enfoque de privacidad y } \\
\text { seguridad, uso ético y legal, actitud crítica en el uso y creación de contenido. }\end{array}$ & $\begin{array}{lllrr}\text { 5.1. Ética, Equidad y } & \text { Responsabilidad } \\
\text { 5.2. } & & & \text { Seguridad } \\
\text { 5.3. Derechos de } & \text { autor } & \text { y } & \text { licencias } \\
\text { 5.4. } & \text { Análisis del } & \text { impacto } & \text { mediático } \\
\text { 5.5. Protección del medio ambiente } & \end{array}$ \\
\hline \multirow[t]{2}{*}{ Social } & $\mathrm{D}$ & $\begin{array}{l}\text { Comunicador } \\
\text { colaborativo }\end{array}$ & $\begin{array}{l}\text { Comunicación y } \\
\text { colaboración }\end{array}$ & $\begin{array}{l}\text { Marcos Unesco y UE: "Implica interactuar, comunicar y colaborar a través de las tecnologías } \\
\text { digitales siendo consciente de la diversidad cultural y generacional. Participar en la sociedad a } \\
\text { través de los servicios digitales públicos y privados y la ciudadanía participativa". } \\
\text { Marco NAEP: "La construcción e intercambio de ideas y soluciones es un conjunto esencial de } \\
\text { habilidades necesarias para utilizar la tecnología de la información y la comunicación (TIC) y los } \\
\text { medios para comunicar ideas y colaborar con otros" }\end{array}$ & 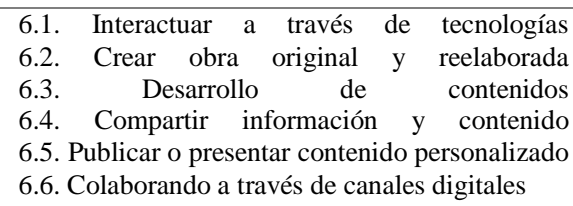 \\
\hline & $\mathrm{T}$ & $\begin{array}{c}\text { Ciudadano } \\
\text { global }\end{array}$ & $\begin{array}{l}\text { Ciudadanía global } \\
\text { y conciencia } \\
\text { multicultural }\end{array}$ & $\begin{array}{l}\text { Marco enGauge: "Conciencia global. El reconocimiento y comprensión de las interrelaciones } \\
\text { entre organizaciones internacionales, estados-nación, entidades económicas públicas y privadas, } \\
\text { grupos socioculturales e individuos en todo el mundo". } \\
\text { Marco enGauge: "Alfabetización multicultural. Capacidad de comprender y apreciar las } \\
\text { similitudes y diferencias en las costumbres, valores y creencias de la cultura propia y las culturas } \\
\text { de } \quad \text { demás. } \\
\text { Marco NETS: "Colaborador global. Utiliza herramientas digitales para ampliar sus perspectivas y } \\
\text { enriquecer su aprendizaje colaborando con otros y trabajando eficazmente en equipos a nivel local } \\
\text { y global". } \\
\text { Marco ATCS: "La ciudadanía global puede describirse ampliamente como un sentido de } \\
\text { identidad colectiva y perteneciente a una comunidad global, con la implicación de que las personas } \\
\text { están conectadas de múltiples formas entre sí y con sus entornos". }\end{array}$ & $\begin{array}{l}\text { 7.1. Participar en la ciudadanía en línea } \\
\text { 7.2. Responsabilidad social y rívica } \\
\text { 7.3. Conciliar tensiones y dilemas } \\
\text { 7.4. Valor de la diversidad } \\
\text { 7.5. Exhibir una sensibilidad informada } \\
\text { 7.6. Participar activamente en otras culturas } \\
\text { 7.7. } \quad \text { Conciencia } \\
\text { 7.8. Económica y financiera }\end{array}$ \\
\hline Emocional & $\mathrm{T}$ & $\begin{array}{c}\text { Líder } \\
\text { empoderado }\end{array}$ & Interpersonal & $\begin{array}{l}\text { Marco enGauge: "Capacidad de leer y manejar las emociones, motivaciones y comportamientos } \\
\text { de uno mismo y de los demás durante las interacciones sociales o en un contexto social- } \\
\text { interactivo". } \\
\text { Shek, Yu, \& Siu (2015) "Se han desarrollado varios enfoques para medir la competencia } \\
\text { interpersonal, centrándose en diferentes índices de 'funcionamiento social exitoso' (...) } \\
\text { Espećficamente, el enfoque funcional de las relaciones interpersonales se centra en los resultados } \\
\text { del comportamiento social. Tener un alto nivel de competencia interpersonal requiere diferentes } \\
\text { habilidades, incluida la interacción y la iniciación de relaciones, la afirmación de los derechos } \\
\text { personales y el descontento con los demás, apertura, apoyo emocional y manejo de conflicto } \\
\text { interpersonal" }\end{array}$ & 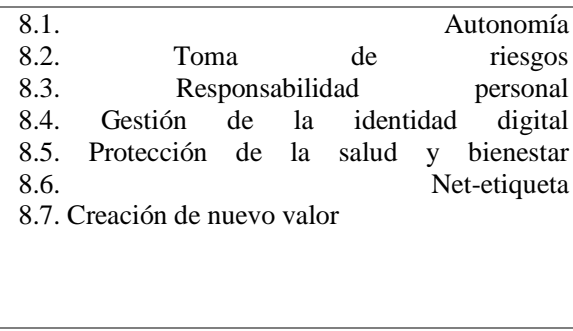 \\
\hline yectiva & $\mathrm{T}$ & $\begin{array}{l}\text { Visionario } \\
\text { Innovador }\end{array}$ & $\begin{array}{l}\text { Pensamiento de } \\
\text { futuro }\end{array}$ & $\begin{array}{l}\text { Atance \& O'Neill (2005). "Capacidad de proyectarse hacia el futuro para pre-experimentar un } \\
\text { evento" } \\
\text { Marco OCDE: "Capacidad no solo para responder a eventos actuales sino para anticipar eventos } \\
\text { futuros. Esto requiere que el alumno sea proactivo: prever y estar dispuesto a actuar sobre lo que } \\
\text { pueda ser necesario para el futuro" }\end{array}$ & 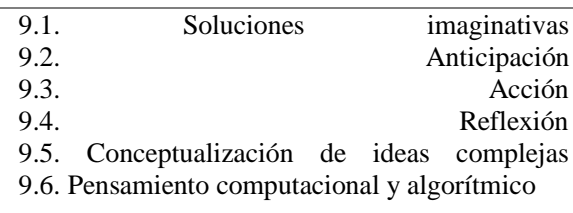 \\
\hline
\end{tabular}

Recibido: 13/05/2021. Aceptado: 21/06/2021. Publicado: 09/07/2021 
RLCS, Revista Latina de Comunicación Social, 79, 1-16

[Investigación] DOI: 10.4185/RLCS-2020-1434| ISSN 1138-5820| Año 2021

Anexo 4. Meta-marco de la alfabetización digital - Descripción de habilidades identificadas en los marcos estudiados

\begin{tabular}{|c|c|c|c|c|}
\hline Dimensión & Competencias & Habilidades & Framework & Descripción de habilidades en los frameworks \\
\hline \multirow{8}{*}{ Cognitiva } & \multirow{4}{*}{$\begin{array}{l}\text { Pensamiento } \\
\text { creativo }\end{array}$} & 1.1. Creatividad & enGauge & $\begin{array}{l}\text { El acto de dar existencia a algo que es genuinamente nuevo } \\
\text { y original. }\end{array}$ \\
\hline & & 1.2. Curiosidad & enGauge & $\begin{array}{l}\text { El deseo de saber o la chispa del interés que lleva a la } \\
\text { indagación. }\end{array}$ \\
\hline & & $\begin{array}{l}\text { 1.3. Adaptabilidad y gestión de la } \\
\text { complejidad }\end{array}$ & enGauge & $\begin{array}{l}\text { La capacidad de modificar el pensamiento, la actitud o el } \\
\text { comportamiento de uno para adaptarse mejor a los entornos } \\
\text { actuales o futuros; y la capacidad de manejar múltiples } \\
\text { objetivos, tareas e insumos, mientras se comprenden y se } \\
\text { adhieren a las limitaciones de tiempo, recursos y sistemas. }\end{array}$ \\
\hline & & $\begin{array}{l}\text { 1.4. Innovacción con herramientas } \\
\text { digitales }\end{array}$ & UE & $\begin{array}{l}\text { Innovar con la tecnología, participar activamente en la } \\
\text { producción colaborativa digital y multimedia, expresarse } \\
\text { creativamente a través de medios y tecnologías digitales, } \\
\text { generar conocimiento y resolver problemas conceptuales } \\
\text { con el apoyo de herramientas digitales. }\end{array}$ \\
\hline & \multirow{4}{*}{$\begin{array}{l}\text { Resolución de } \\
\text { problemas }\end{array}$} & $\begin{array}{l}\text { 2.1. Pensamiento de orden superior y } \\
\text { razonamiento sólido }\end{array}$ & enGauge & $\begin{array}{l}\text { Los procesos cognitivos de análisis, comparación, } \\
\text { inferencia e interpretación, evaluación y síntesis aplicados a } \\
\text { una variedad de dominios académicos y contextos de } \\
\text { resolución de problemas. }\end{array}$ \\
\hline & & 2.2. Productividad & enGauge & $\begin{array}{l}\text { Priorización, planificación y gestión orientada a resultados. } \\
\text { La capacidad de organizarse para lograr de manera eficiente } \\
\text { los objetivos de un proyecto o problema específico. La } \\
\text { capacidad de utilizar herramientas del mundo real para } \\
\text { comunicarse, colaborar, resolver problemas y realizar } \\
\text { tareas. La capacidad de producir productos intelectuales, } \\
\text { informativos o materiales que sirven a propósitos auténticos } \\
\text { y ocurren como resultado de que los estudiantes usen } \\
\text { herramientas del mundo real para resolver o comunicarse } \\
\text { sobre problemas del mundo real. }\end{array}$ \\
\hline & & $\begin{array}{l}\text { 2.3. Identificación de brecha de } \\
\text { competencia digital }\end{array}$ & OCDE & $\begin{array}{l}\text { Entender dónde debe mejorarse o actualizarse la propia } \\
\text { competencia digital. Poder apoyar a otros en el desarrollo } \\
\text { de sus competencias digitales. Buscar oportunidades de } \\
\text { autodesarrollo y estar al día de la evolución digital. }\end{array}$ \\
\hline & & 2.4. Pensamiento científico & enGauge & $\begin{array}{l}\text { Conocimiento y comprensión de los conceptos y procesos } \\
\text { científicos necesarios para la toma de decisiones } \\
\text { personales, la participación en asuntos cívicos y culturales y } \\
\text { la productividad económica. La alfabetización científica es } \\
\text { importante a lo largo de la vida de los estudiantes, ya que } \\
\text { participan en cuestiones de política pública relacionadas } \\
\text { con la tecnología; a medida que se mantienen actualizados } \\
\text { con los avances en áreas como la biotecnología, la medicina } \\
\text { y la exploración espacial; y especialmente a medida que } \\
\text { ingresan a una fuerza laboral cada vez más basada en la } \\
\text { ciencia }\end{array}$ \\
\hline \multirow{6}{*}{ Operativa } & \multirow{6}{*}{ Técnica } & $\begin{array}{l}\text { 3.1. Comprensión conceptual de la } \\
\text { naturaleza de la tecnología }\end{array}$ & enGauge & $\begin{array}{l}\text { Demostrar una sólida comprensión conceptual de la } \\
\text { naturaleza de los sistemas tecnológicos y verse a sí mismos } \\
\text { como usuarios competentes de estos sistemas. }\end{array}$ \\
\hline & & 3.2. Operación de hardware y software & Unesco & $\begin{array}{l}\text { Operación física de dispositivos digitales: Identificar y } \\
\text { utilizar las funciones y características de las herramientas y } \\
\text { tecnologías de hardware. Operación de software en } \\
\text { dispositivos digitales: Conocer y comprender los datos, } \\
\text { información y / o contenido digital que se necesitan para } \\
\text { operar herramientas y tecnologías de software. }\end{array}$ \\
\hline & & $\begin{array}{l}\text { 3.3. Identificación de necesidades y } \\
\text { respuestas tecnológicas }\end{array}$ & UE & $\begin{array}{l}\text { Evaluar las necesidades propias en términos de recursos, } \\
\text { herramientas y desarrollo de competencias, para hacer } \\
\text { coincidir las necesidades con las posibles soluciones, } \\
\text { adaptando las herramientas a las necesidades personales, } \\
\text { para evaluar críticamente las posibles soluciones y } \\
\text { herramientas digitales. }\end{array}$ \\
\hline & & $\begin{array}{l}\text { 3.4. Mantenimiento y resolución de } \\
\text { problemas técnico }\end{array}$ & NAEP & $\begin{array}{l}\text { El mantenimiento y la resolución de problemas es el } \\
\text { conjunto de métodos utilizados para evitar que los } \\
\text { dispositivos y sistemas tecnológicos se averíen y para } \\
\text { diagnosticarlos y repararlos cuando fallan. }\end{array}$ \\
\hline & & 3.5. Pensamiento sistémico & NAEP & $\begin{array}{l}\text { Es una forma de pensar en dispositivos y situaciones para } \\
\text { comprender mejor las interacciones entre componentes, las } \\
\text { causas fundamentales de los problemas y las consecuencias } \\
\text { de diversas soluciones. }\end{array}$ \\
\hline & & 3.6. Diseño de ingeniería & NAEP & $\begin{array}{l}\text { Enfoque sistemático para crear soluciones a problemas } \\
\text { tecnológicos } \mathrm{y} \text { encontrar formas de satisfacer las }\end{array}$ \\
\hline
\end{tabular}


RLCS, Revista Latina de Comunicación Social, 79, 1-16

[Investigación] DOI: 10.4185/RLCS-2020-1434| ISSN 1138-5820| Año 2021

\begin{tabular}{|c|c|c|c|c|}
\hline & & & & necesidades y deseos de las personas. \\
\hline & & 3.7. Programación & Unesco & $\begin{array}{l}\text { Planificar y desarrollar una secuencia de instrucciones } \\
\text { comprensibles para que un sistema informático resuelva un } \\
\text { problema determinado o realice una tarea específica. }\end{array}$ \\
\hline & & $\begin{array}{l}\text { 3.8. Uso de la tecnología relacionado } \\
\text { con la profesión }\end{array}$ & Unesco & $\begin{array}{l}\text { Operar tecnologías digitales especializadas para un campo } \\
\text { en particular: Identificar y utilizar herramientas y } \\
\text { tecnologías digitales especializadas para un campo en } \\
\text { particular. Interpretar y manipular datos, información y } \\
\text { contenido digital para un campo en particular: Comprender, } \\
\text { analizar y evaluar datos, información y contenido digital } \\
\text { especializados para un campo en particular dentro de un } \\
\text { entorno digital. }\end{array}$ \\
\hline \multirow{10}{*}{ Crítica } & \multirow{5}{*}{$\begin{array}{l}\text { Información y } \\
\text { datos }\end{array}$} & $\begin{array}{l}\text { 5.1. Navegación, búsqueda y filtrado de } \\
\text { datos, información y contenido digital } \\
\text { (UE). }\end{array}$ & UE & $\begin{array}{l}\text { Acceder y buscar información en línea, articular las } \\
\text { necesidades de información, encontrar información } \\
\text { relevante, seleccionar recursos de manera efectiva, navegar } \\
\text { entre fuentes en línea, crear estrategias de información } \\
\text { personal. }\end{array}$ \\
\hline & & $\begin{array}{l}\text { 5.2. Evaluación de datos, información y } \\
\text { contenido digital }\end{array}$ & Unesco & $\begin{array}{l}\text { Analizar, comparar y evaluar críticamente la credibilidad y } \\
\text { confiabilidad de las fuentes de datos, información y } \\
\text { contenido digital. Analizar, interpretar y evaluar } \\
\text { críticamente los datos, la información y el contenido digital. }\end{array}$ \\
\hline & & $\begin{array}{l}\text { 5.3. Gestión de datos, información y } \\
\text { contenido digital }\end{array}$ & Unesco & $\begin{array}{l}\text { Organizar, almacenar y recuperar datos, información y } \\
\text { contenido en entornos digitales. Organizarlos y procesarlos } \\
\text { en un entorno estructurado. }\end{array}$ \\
\hline & & $\begin{array}{l}\text { 5.4. Analizar e interpretar propuestas y } \\
\text { mensajes }\end{array}$ & $\mathrm{P} 21$ & $\begin{array}{l}\text { Comprender cómo y por qué se construyen los mensajes de } \\
\text { los medios y con qué fines. }\end{array}$ \\
\hline & & 5.5. Producción y diseño visual & enGauge & $\begin{array}{l}\text { Tener conocimiento práctico de los elementos visuales } \\
\text { producidos o exhibidos a través de medios electrónicos: } \\
\text { Comprender los elementos básicos del diseño visual, la } \\
\text { técnica y los medios. Consciencia de las influencias } \\
\text { emocionales, psicológicas, fisiológicas y cognitivas en las } \\
\text { percepciones de las imágenes. Comprender imágenes } \\
\text { representativas, explicativas, abstractas y simbólicas. } \\
\text { Aplicar el conocimiento de las imágenes en los medios } \\
\text { electrónicos: son espectadores informados, críticos y } \\
\text { consumidores de información visual. Son diseñadores, } \\
\text { compositores y productores de información visual expertos. } \\
\text { Son comunicadores visuales eficaces. }\end{array}$ \\
\hline & \multirow{5}{*}{$\begin{array}{l}\text { Pensamiento } \\
\text { crítico }\end{array}$} & 6.1. Ética, Equidad y Responsabilidad & NAEP & $\begin{array}{l}\text { Se refiere a los profundos efectos que tienen las tecnologías } \\
\text { en las personas, cómo esos efectos pueden ampliar o } \\
\text { reducir las disparidades y la responsabilidad que tienen las } \\
\text { personas por las consecuencias sociales de sus decisiones } \\
\text { tecnológicas. }\end{array}$ \\
\hline & & 6.2. Seguridad & Unesco & $\begin{array}{l}\text { Protección de dispositivos: proteger dispositivos y } \\
\text { contenido digital, comprender los riesgos y amenazas en } \\
\text { entornos digitales. Conocer las medidas de seguridad y } \\
\text { protección y tener debidamente en cuenta la fiabilidad y la } \\
\text { privacidad. Protección de los datos personales y la } \\
\text { privacidad: para proteger los datos personales y la } \\
\text { privacidad en entornos digitales. Comprender cómo usar y } \\
\text { compartir información de identificación personal mientras } \\
\text { puede protegerse a sí mismo y a los demás de daños. Para } \\
\text { comprender que los servicios digitales utilizan una "Política } \\
\text { de privacidad" para informar cómo se utilizan los datos } \\
\text { personales. }\end{array}$ \\
\hline & & 6.3. Derechos de autor y licencias & Unesco & $\begin{array}{l}\text { Comprender cómo se aplican los derechos de autor y las } \\
\text { licencias a los datos, la información y el contenido digital. }\end{array}$ \\
\hline & & 6.4. Análisis del impacto mediático & $\mathrm{P} 21$ & $\begin{array}{l}\text { Examinar cómo las personas interpretan los mensajes de } \\
\text { manera diferente, cómo se incluyen o excluyen los valores } \\
\text { y puntos de vista, y cómo los medios pueden influir en las } \\
\text { creencias y los comportamientos. }\end{array}$ \\
\hline & & 6.5. Protección del medio ambiente & Unesco & $\begin{array}{l}\text { Conocer el impacto ambiental de las tecnologías digitales y } \\
\text { su uso. }\end{array}$ \\
\hline \multirow[t]{2}{*}{ Social } & \multirow[t]{2}{*}{$\begin{array}{l}\text { Comunicación } \\
\text { y colaboración }\end{array}$} & 7.1. Interactuar a través de tecnologías & UE & $\begin{array}{l}\text { Interactuar a través de una variedad de dispositivos y } \\
\text { aplicaciones digitales, comprender cómo se distribuye, } \\
\text { muestra y administra la comunicación digital, comprender } \\
\text { las formas apropiadas de comunicarse a través de medios } \\
\text { digitales, referirse a diferentes formatos de comunicación, } \\
\text { adaptar modos y estrategias de comunicación a la audiencia } \\
\text { específica. }\end{array}$ \\
\hline & & 7.2. Crear obra original y re-elaborada & NAEP & $\begin{array}{l}\text { Creación de trabajos originales o que reutilice o mezcle de } \\
\text { manera responsable los recursos digitales en nuevas } \\
\text { creaciones. }\end{array}$ \\
\hline
\end{tabular}


RLCS, Revista Latina de Comunicación Social, 79, 1-16

[Investigación] DOI: 10.4185/RLCS-2020-1434| ISSN 1138-5820| Año 2021

\begin{tabular}{|c|c|c|c|}
\hline & 7.3. Desarrollo de contenidos & UE & $\begin{array}{l}\text { Crear contenido en diferentes formatos incluyendo } \\
\text { multimedia, editar y mejorar contenido que ha creado o que } \\
\text { otros han creado, expresarse creativamente a través de } \\
\text { medios y tecnologías digitales. }\end{array}$ \\
\hline & 7.4. Compartir información y contenido & UE & $\begin{array}{l}\text { Compartir con otros la ubicación y el contenido de la } \\
\text { información encontrada, estar dispuesto y ser capaz de } \\
\text { compartir conocimientos, contenidos y recursos, actuar } \\
\text { como intermediario, ser proactivo en la difusión de noticias, } \\
\text { contenidos y recursos, conocer las prácticas de citación y } \\
\text { para integrar nueva información en un cuerpo de } \\
\text { conocimiento existente. }\end{array}$ \\
\hline & \begin{tabular}{|l|l|}
$\begin{array}{l}\text { 7.5. Publicar o presentar contenido } \\
\text { personalizado }\end{array}$ & \\
\end{tabular} & NAEP & $\begin{array}{l}\text { Publicar o presentar contenido que personalice el mensaje y } \\
\text { el medio para sus audiencias objetivo. }\end{array}$ \\
\hline & $\begin{array}{l}\text { 7.6. Colaborando a través de canales } \\
\text { digitales }\end{array}$ & UE & $\begin{array}{l}\text { Utilizar tecnologías y medios para el trabajo en equipo, } \\
\text { procesos colaborativos y co-construcción y co-creación de } \\
\text { recursos, conocimientos y contenidos. }\end{array}$ \\
\hline \multirow{8}{*}{$\begin{array}{l}\text { Ciudadanía } \\
\text { global y } \\
\text { conciencia } \\
\text { multicultural }\end{array}$} & 8.1. Participar en la ciudadanía en línea & $\begin{array}{l}\text { NETS } \\
\text { UE }\end{array}$ & $\begin{array}{l}\text { Reconocen los derechos, responsabilidades y oportunidades } \\
\text { de vivir, aprender y trabajar en un mundo digital } \\
\text { interconectado, y actúan y modelan de manera segura, legal } \\
\text { y ética. Participar en la sociedad a través del compromiso } \\
\text { en línea, buscar oportunidades de autodesarrollo y } \\
\text { empoderamiento en el uso de tecnologías y entornos } \\
\text { digitales, ser conscientes del potencial de las tecnologías } \\
\text { para la participación ciudadana. }\end{array}$ \\
\hline & 8.2. Responsabilidad social y cívica & enGauge & $\begin{array}{l}\text { La capacidad de administrar la tecnología y gobernar su uso } \\
\text { de una manera que promueva el bien público y proteja la } \\
\text { sociedad, el medio ambiente y los ideales democráticos. }\end{array}$ \\
\hline & 8.3. Conciliar tensiones y dilemas & OCDE & $\begin{array}{l}\text { Capacidad para manejar tensiones, dilemas y } \\
\text { compensaciones, por ejemplo, entre equidad y libertad; } \\
\text { autonomía y solidaridad; eficiencia y procesos } \\
\text { democráticos; ecología y modelos económicos simplistas; } \\
\text { diversidad y universalidad; e innovación y continuidad. } \\
\text { Esto requiere la habilidad de equilibrar demandas } \\
\text { aparentemente contradictorias o incompatibles. } \\
\text { Comprender las necesidades y los intereses de los demás es } \\
\text { fundamental para garantizar el bienestar propio y el de las } \\
\text { familias y las comunidades a lo largo del tiempo. Por lo } \\
\text { tanto, es esencial desarrollar la capacidad para comprender } \\
\text { y trabajar junto con las necesidades, los intereses y las } \\
\text { perspectivas de los demás. El desafío consiste en reconciliar } \\
\text { múltiples ideas o posiciones, a menudo en conflicto, y } \\
\text { reconocer que puede haber más de una solución o método } \\
\text { para encontrar una solución. }\end{array}$ \\
\hline & 8.4. Valor de la diversidad & enGauge & $\begin{array}{l}\text { Consciencia de cómo las creencias, valores y sensibilidades } \\
\text { culturales afectan la forma en que ellos y los demás piensan } \\
\text { y se comportan: Aprecian y aceptan las similitudes y } \\
\text { diferencias en creencias, apariencias y estilos de vida; } \\
\text { Comprender cómo la tecnología impacta la cultura. }\end{array}$ \\
\hline & 8.5. Exhibir una sensibilidad informada & enGauge & $\begin{array}{l}\text { Conocer la historia de las culturas tanto dominantes como } \\
\text { no dominantes. Tomar las perspectivas de otros grupos } \\
\text { culturales. Ser sensibles a cuestiones de prejuicio, racismo, } \\
\text { prejuicios y estereotipos. }\end{array}$ \\
\hline & $\begin{array}{l}\text { 8.6. Participar activamente en otras } \\
\text { culturas }\end{array}$ & enGauge & $\begin{array}{l}\text { Ser bilingües / multilingües o estar trabajando para } \\
\text { convertirse en bilingües / multilingües. Comunicarse, } \\
\text { interactuar y trabajar con personas de otros grupos } \\
\text { culturales, utilizando tecnología cuando sea apropiado. } \\
\text { Estar familiarizados con las normas culturales de los } \\
\text { entornos tecnológicos para interactuar con éxito en dichos } \\
\text { entornos. }\end{array}$ \\
\hline & 8.7. Conciencia global & enGauge & $\begin{array}{l}\text { Conocer la conexión de las naciones del mundo a nivel } \\
\text { histórico, político, económico, tecnológico, social, } \\
\text { lingüístico y ecológicamente. Ser capaces de reconocer, } \\
\text { analizar y evaluar las principales tendencias en las } \\
\text { relaciones globales y las interconexiones de estas } \\
\text { tendencias con sus comunidades locales y nacionales. } \\
\text { Entender cómo las diferencias culturales nacionales } \\
\text { impactan la interpretación de eventos a nivel global. } \\
\text { Comprender el impacto de la ideología y la cultura en las } \\
\text { decisiones nacionales sobre el acceso y el uso de la } \\
\text { tecnología. }\end{array}$ \\
\hline & 8.8. Económica y financiera & enGauge & $\begin{array}{l}\text { Capacidad de identificar problemas económicos, } \\
\text { alternativas, costos y beneficios; analizar los incentivos en } \\
\text { el trabajo en situaciones económicas; examinar las } \\
\text { consecuencias de los cambios en las condiciones } \\
\text { económicas y las políticas públicas; recopilar y organizar }\end{array}$ \\
\hline
\end{tabular}


RLCS, Revista Latina de Comunicación Social, 79, 1-16

[Investigación] DOI: 10.4185/RLCS-2020-1434| ISSN 1138-5820| Año 2021

\begin{tabular}{|c|c|c|c|c|}
\hline & & & & $\begin{array}{l}\text { pruebas económicas; y sopesar los costos con los } \\
\text { beneficios. }\end{array}$ \\
\hline \multirow{7}{*}{ Emocional } & \multirow{7}{*}{ Interpersonal } & 9.1. Autonomía & enGauge & $\begin{array}{l}\text { Capacidad de establecer metas relacionadas con el } \\
\text { aprendizaje, planificar el logro de esas metas, administrar el } \\
\text { tiempo y el esfuerzo de forma independiente y evaluar de } \\
\text { forma independiente la calidad del aprendizaje y cualquier } \\
\text { producto que resulte de la experiencia de aprendizaje. }\end{array}$ \\
\hline & & 9.2. Toma de riesgos & enGauge & $\begin{array}{l}\text { Disposición a cometer errores, defender posiciones poco } \\
\text { convencionales o impopulares, o abordar problemas } \\
\text { extremadamente desafiantes sin soluciones obvias, de modo } \\
\text { que mejoren el crecimiento personal, la integridad o los } \\
\text { logros. }\end{array}$ \\
\hline & & 9.3. Responsabilidad personal & enGauge & $\begin{array}{l}\text { Profundidad y actualidad del conocimiento sobre cuestiones } \\
\text { legales y éticas relacionadas con la tecnología, combinado } \\
\text { con la capacidad de uno para aplicar este conocimiento para } \\
\text { lograr el equilibrio, la integridad y la calidad de vida como } \\
\text { ciudadano, miembro de la familia y la comunidad, aprendiz } \\
\text { y trabajador. }\end{array}$ \\
\hline & & 9.4. Gestión de la identidad digital & UE & $\begin{array}{l}\text { Crear, adaptar y gestionar una o varias identidades } \\
\text { digitales, poder proteger la propia reputación electrónica, } \\
\text { tratar los datos que se producen a través de varias cuentas y } \\
\text { aplicaciones. }\end{array}$ \\
\hline & & 9.5. Protección de la salud y bienestar & Unesco & $\begin{array}{l}\text { Protección de la salud y el bienestar: poder evitar los } \\
\text { riesgos para la salud y las amenazas al bienestar físico y } \\
\text { psicológico mediante el uso de tecnologías digitales. Ser } \\
\text { capaz de protegerse a sí mismo y a los demás de posibles } \\
\text { peligros en entornos digitales (por ejemplo, ciberacoso). } \\
\text { Conocer las tecnologías digitales para el bienestar social y } \\
\text { la inclusión social. }\end{array}$ \\
\hline & & 9.6. Net-etiqueta & UE & $\begin{array}{l}\text { Tener el conocimiento y el know-how de las normas de } \\
\text { comportamiento en las interacciones virtuales / en línea }\end{array}$ \\
\hline & & 9.7. Creación de nuevo valor & OCDE & $\begin{array}{l}\text { Se refiere a la capacidad de una persona para innovar y } \\
\text { actuar de manera emprendedora, en un sentido general, } \\
\text { tomando acciones informadas y responsables. Para crear un } \\
\text { nuevo valor, los estudiantes deben tener un sentido de } \\
\text { propósito, curiosidad y una mentalidad abierta hacia nuevas } \\
\text { ideas, perspectivas y experiencias. Crear nuevo valor } \\
\text { requiere pensamiento crítico y creatividad para encontrar } \\
\text { diferentes enfoques para resolver problemas y la } \\
\text { colaboración con otros para encontrar soluciones a } \\
\text { problemas complejos. Al evaluar si sus soluciones } \\
\text { funcionan o no, los estudiantes pueden necesitar agilidad } \\
\text { para probar nuevas ideas y pueden necesitar ser capaces de } \\
\text { gestionar los riesgos asociados con estas nuevas ideas. Los } \\
\text { estudiantes también necesitan adaptabilidad a medida que } \\
\text { cambian sus enfoques basados en conocimientos y } \\
\text { hallazgos nuevos y emergentes. }\end{array}$ \\
\hline \multirow[b]{2}{*}{ Proyectiva } & \multirow[b]{2}{*}{$\begin{array}{l}\text { Pensamiento de } \\
\text { futuro }\end{array}$} & 10.1. Soluciones imaginativas & NETS & $\begin{array}{l}\text { Conocer y utilizar un proceso de diseño deliberado para } \\
\text { generar ideas, probar teorías, crear artefactos innovadores o } \\
\text { resolver problemas auténticos. Seleccionar y utilizar } \\
\text { herramientas digitales para planificar y gestionar un } \\
\text { proceso de diseño que considere las limitaciones del diseño } \\
\text { y los riesgos calculados. Desarrollar, probar y perfeccionar } \\
\text { prototipos como parte de un proceso de diseño cíclico. } \\
\text { Mostrar tolerancia a la ambigüedad, perseverancia y } \\
\text { capacidad para trabajar con problemas abiertos. }\end{array}$ \\
\hline & & 10.2. Anticipación & OCDE & $\begin{array}{l}\text { Capacidad de desarrollar la conciencia de cómo las } \\
\text { acciones tomadas hoy pueden tener consecuencias en el } \\
\text { futuro. La anticipación requiere algo más que hacer } \\
\text { preguntas; implica proyectar las consecuencias y el impacto } \\
\text { potencial de hacer una cosa sobre otra, o de no hacer nada } \\
\text { en absoluto. Al anticipar, los estudiantes utilizan su } \\
\text { capacidad para comprender los problemas, manejar } \\
\text { tensiones y dilemas y considerar las consecuencias a corto y } \\
\text { largo plazo que resultan de sus acciones (o inacción). Los } \\
\text { estudiantes también consideran cómo la resolución de un } \\
\text { problema o la creación de nuevo valor anticipa las } \\
\text { necesidades futuras. Un elemento crítico de la anticipación } \\
\text { es la prospección: la capacidad de "preexperimentar el } \\
\text { futuro simulándolo en [la] mente". La prospección permite } \\
\text { al alumno considerar y predecir los diferentes resultados } \\
\text { posibles de sus acciones potenciales. }\end{array}$ \\
\hline
\end{tabular}


RLCS, Revista Latina de Comunicación Social, 79, 1-16

[Investigación] DOI: 10.4185/RLCS-2020-1434| ISSN 1138-5820| Año 2021

\begin{tabular}{|c|c|c|}
\hline 10.3. Acción & OCDE & $\begin{array}{l}\text { La acción es un puente entre lo que los alumnos ya saben y } \\
\text { lo que quieren hacer realidad. A través de la anticipación, el } \\
\text { alumno define una meta y un propósito para actuar. Las } \\
\text { acciones pueden ser de investigación, pueden estar } \\
\text { orientadas a asumir responsabilidades o crear nuevo valor, } \\
\text { o pueden estar dirigidas a realizar cambios. Las acciones } \\
\text { pueden ser individuales, comunes o colectivas. }\end{array}$ \\
\hline 10.4. Reflexión & OCDE & $\begin{array}{l}\text { "El proceso de creación de significado que mueve a un } \\
\text { alumno de una experiencia a la siguiente con una } \\
\text { comprensión más profunda de sus relaciones y conexiones } \\
\text { con otras experiencias e ideas". La reflexión es el hilo } \\
\text { conductor que posibilita la continuidad del aprendizaje. } \\
\text { Permite a los alumnos mejorar su pensamiento, lo que } \\
\text { conduce a mejores acciones hacia el bienestar a lo largo del } \\
\text { tiempo. A través de la reflexión, los alumnos adquieren un } \\
\text { sentido de poder sobre sus acciones futuras, y un sentido de } \\
\text { dirección, que los lleva al desarrollo de la agencia. La } \\
\text { reflexión es una forma de pensar sistemática, rigurosa y } \\
\text { disciplinada, con sus raíces en la investigación científica. } \\
\text { La reflexión implica el uso combinado de habilidades } \\
\text { autodirigidas y habilidades de pensamiento creativo, y } \\
\text { abarca la motivación, la ética y los componentes sociales y } \\
\text { conductuales, además de los componentes cognitivos. }\end{array}$ \\
\hline $\begin{array}{l}\text { 10.5. Conceptualización e ideas } \\
\text { complejas de forma clara y eficaz }\end{array}$ & NAEP & $\begin{array}{l}\text { Comunicación de ideas complejas de forma clara y eficaz } \\
\text { mediante la creación o el uso de una variedad de objetos } \\
\text { digitales como visualizaciones, modelos o simulaciones. }\end{array}$ \\
\hline $\begin{array}{l}\text { 10.6. Pensamiento computacional y } \\
\text { algorítmico }\end{array}$ & NETS & $\begin{array}{l}\text { Formular definiciones de problemas adecuadas para } \\
\text { métodos asistidos por tecnología, como análisis de datos, } \\
\text { modelos abstractos y pensamiento algorítmico para } \\
\text { explorar y encontrar soluciones. Recopilación de datos o } \\
\text { identificación de conjuntos de datos relevantes, } \\
\text { herramientas digitales para analizarlos y representar los } \\
\text { datos de diversas formas para facilitar la resolución de } \\
\text { problemas y la toma de decisiones. Dividir los problemas } \\
\text { en componentes, extraer información clave y desarrollar } \\
\text { modelos descriptivos para comprender sistemas complejos } \\
\text { o facilitar la resolución de problemas. Comprensión de } \\
\text { cómo funciona la automatización y utilizar el pensamiento } \\
\text { algorítmico para desarrollar una secuencia de pasos para } \\
\text { crear y probar soluciones automatizadas. }\end{array}$ \\
\hline
\end{tabular}

Fuente: Elaboración propia a partir de marcos: ATCS, enGauge, Naep, Nets, OCDE, P21, Unesco, UE. 